\title{
Effect of Nilotinib on Bleomycin-Induced Acute Lung Injury and Pulmonary Fibrosis in Mice
}

\author{
Chin Kook Rhee ${ }^{a}$ Sang Haak Lee ${ }^{a}$ Hyung Kyu Yoon ${ }^{a}$ Seok Chan Kim ${ }^{a}$ \\ Sook Young Lee ${ }^{a}$ Soon Suk Kwon ${ }^{a}$ Young Kyoon Kim ${ }^{a}$ Kwan Hyoung Kim ${ }^{a}$ \\ Tae Jung Kimb Jin Woo Kim ${ }^{\mathrm{a}}$ \\ ${ }^{a}$ Department of Internal Medicine, Division of Pulmonary and Critical Care Medicine and ${ }^{b}$ Department of \\ Hospital Pathology, College of Medicine, Catholic University of Korea, Seoul, Korea
}

\section{Key Words}

Nilotinib $\cdot$ Imatinib $\cdot$ Acute lung injury $\cdot$ Pulmonary

fibrosis $\cdot$ Platelet-derived growth factor $\cdot$ Transforming

growth factor- $\beta$

\section{Abstract}

Background: The tyrosine kinase inhibitor imatinib mesylate was developed as an inhibitor of the kinase activity of BCR-ABL. However, imatinib also has potent inhibitory activity against the platelet-derived growth factor receptor (PDGFR). Nilotinib is approved for treating patients with chronic myeloid leukemia showing resistance or intolerance to imatinib. Like imatinib, nilotinib selectively inhibits the tyrosine kinase activity of PDGFR. Objectives: We examined the effect of imatinib and nilotinib on acute lung injury and pulmonary fibrosis in a mouse model. Methods: Mice were treated by intratracheal instillation of bleomycin. Imatinib or nilotinib were administered by oral gavage. To study the early inflammatory and late fibrotic phases of lung injury, mice were sacrificed on days 3, 7, 14 and 21 after bleomycin instillation. Results: Histopathology showed that imatinib and nilotinib attenuated the extent of lung injury and fibrosis. The numbers of inflammatory cells and levels of IL- $6, \mathrm{IL}-1 \beta$ and tumor necrosis factor- $\alpha$ were decreased in the imatinib and nilotinib groups on days 3 and 7. Imatinib and nilotinib therapy significantly reduced the levels of hydroxyproline on days 14 and 21, which was accompanied by decreased expression levels of transforming growth factor (TGF)- $\beta 1$ and PDGFR- $\beta$. Imatinib and nilotinib also significantly reduced the expression levels of the genes for TGF- $\beta 1$ and plateletderived growth factor (PDGF). Imatinib and nilotinib treatment also significantly inhibited the PDGF-induced proliferation of lung fibroblasts in vitro. When imatinib or nilotinib was given 7 days after the instillation of bleomycin, only nilotinib attenuated pulmonary fibrosis. Conclusions: Imatinib and nilotinib attenuated bleomycin-induced acute lung injury and pulmonary fibrosis in mice. In a therapeutic model, nilotinib showed more potent antifibrotic effects than imatinib.

Copyright $\odot 2011$ S. Karger AG, Basel

\section{Introduction}

The annual incidence of acute lung injury (ALI)/acute respiratory distress syndrome (ARDS) in the United States has been estimated at 75 per 100,000 [1]. Despite advances in treatment, mortality remains at approximately $40 \%$ [2]. However, no specific pharmacologic ther-

\section{KARGER}

Fax +4161306 1234

E-Mail karger@karger.ch

www.karger.com (c) $2011 \mathrm{~S}$. Karger AG, Basel

$0025-7931 / 11 / 0823-0273 \$ 38.00 / 0$

Accessible online at:

www.karger.com/res
Jin Woo Kim

Division of Pulmonary and Critical Care Medicine, Department of Internal Medicine, Uijeongbu St. Mary's Hospital, 65-1 Keumho Dong

Uijeongbu City, Kyungki Province 480-717 (Korea)

Tel. +82 318203995 , E-Mail medkjw@ catholic.ac.kr 
apies are available currently. ALI/ARDS is considered to have an early and a late phase. The early phase is characterized by inflammatory injury and the late, so-called fibroproliferative, phase is characterized by collagen deposition with tissue remodeling $[3,4]$. Experimentally, intratracheal delivery of bleomycin has been shown to induce lung injury and fibrosis in a wide variety of experimental animals, including mice [5].

The tyrosine kinase inhibitor imatinib mesylate (STI571, Gleevec ${ }^{\circledR} /$ Glivec $^{\circledR}$; Novartis International AG, Basel, Switzerland) was developed as an inhibitor of the tyrosine kinase activity of the oncogene fusion protein BCR-ABL. Imatinib has shown significant activity in treating patients with chronic myeloid leukemia (CML) $[6,7]$. However, imatinib also has potent inhibitory activity against kinase activity associated with the stem cell factor (c-Kit), discoidin domain receptor and the plateletderived growth factor receptor (PDGFR) $[8,9]$. Imatinib has also demonstrated efficacy against gastrointestinal stromal tumor and hypereosinophilic syndrome, as a result of Kit and PDGFR inhibition [10-12].

Recently, nilotinib (AMN107, Tasigna ${ }^{\circledR}$; Novartis) has been approved for treating patients with BCR-ABL-positive CML with resistance or intolerance to imatinib. Nilotinib is also a small molecule tyrosine kinase inhibitor that can be administrated orally [13]. Like imatinib, nilotinib inhibits the tyrosine kinase activity of Abl-kinase, c-Kit, discoidin domain receptor and PDGFR. Comparison of the half-maximal inhibitory concentration showed nilotinib to be more potent than imatinib. Nilotinib also showed good bioavailability [14]. Consistent with its in vitro and pharmacokinetic profiles, nilotinib prolonged survival in imatinib-resistant CML mouse models [15].

A previous report showed that imatinib could attenuate bleomycin-induced fibrosis in mice [16]. However, that report focused only on fibrosis. Moreover, there has been no study on the effects of nilotinib on bleomycininduced ALI and pulmonary fibrosis. Therefore, the present study aimed to determine whether imatinib and nilotinib could attenuate ALI and pulmonary fibrosis in a mouse model of disease induced by bleomycin and to evaluate their effects on the signal transduction pathway responsible for inflammatory and fibrotic responses.

\section{Methods}

\section{Animals}

Male 6-week-old C57BL6 mice ( $\mathrm{n}=5$ per group; Orient Bio Experimental Animal Center, Kyoungki, Korea) were used. The animals were assigned to one of the following four treatment groups: (1) control; (2) bleomycin; (3) bleomycin plus imatinib (100 mg/kg, twice daily); (4) bleomycin plus nilotinib (100 mg/kg, once daily). In the bleomycin alone group, mice were treated with intratracheal instillation of bleomycin $(1.5 \mathrm{U} / \mathrm{kg}$; Sigma-Aldrich, St. Louis, Mo., USA) on day 0. Control mice received the same protocol but the same volume of saline instead of bleomycin. Imatinib or nilotinib was administrated by oral gavage starting on day 0 and was continued until sacrifice. To study the effect of imatinib and nilotinib on the early inflammatory phase and the late fibrotic phase, mice were sacrificed on days 3, 7, 14 and 21 after bleomycin instillation. This study was approved by the institutional review board of the Catholic University of Korea (Seoul, Korea). All experimental animals were treated according to guidelines approved by the Animal Subjects Committee of the Catholic University of Korea.

\section{Bronchoalveolar Lavage}

Mice were sacrificed by $\mathrm{CO}_{2}$ asphyxiation. The trachea was exposed and cannulated with silicone tubing attached to a 22 -gauge needle on an 800 - $\mu$ l tuberculin syringe. Following instillation of $0.8 \mathrm{ml}$ of sterile phosphate-buffered saline (PBS) through the trachea into the lung, bronchoalveolar lavage (BAL) fluid was withdrawn. Total cell counts in BAL fluid were performed using a hemocytometer. BAL fluid was processed by cytospin $(5 \mathrm{~min}$ at $70 \mathrm{~g}$ ) onto microscope slides and stained with Diff-Quick (Sysmax, Tokyo, Japan). Percentages of BAL fluid macrophages, eosinophils, lymphocytes and neutrophils were obtained by counting 500 leukocytes on randomly selected portions of the slide by light microscopy. Supernatants were stored at $-70^{\circ} \mathrm{C}$.

Enzyme-Linked Immunosorbent Assays

Concentrations of IL- 6 , IL- $1 \beta$ and TNF- $\alpha$ in the BAL fluid were measured using an ELISA kit (R\&D Systems, Minneapolis, Minn., USA). Concentration of TGF- $\beta 1$ in the lung tissue was also measured using an ELISA kit (eBioscience, Hatfield, UK). Acid-activated latent TGF- $\beta 1$ was measured. The protocol followed the manufacturer's instructions.

\section{Morphological Analysis}

Lung tissues were fixed with $4 \%$ paraformaldehyde in PBS and embedded in paraffin wax. Sections were cut at $4 \mu \mathrm{m}$ using a microtome and deparaffinized tissue sections were subjected to hematoxylin and eosin staining for histological examination and Masson's trichrome staining for fibrosis. A pathologist (T.J.K.) then evaluated these tissue sections in a blinded fashion using the following scoring system to grade the degree of lung injury [17]. Features evaluated were focal thickening of the alveolar membranes, congestion, pulmonary edema, intra-alveolar hemorrhage and interstitial as well as intra-alveolar neutrophil infiltrations. Each feature was assigned a score from 0 to 3 based on its absence (0) or presence to a mild (1), moderate (2) or severe (3) degree and a total cumulative histology score was determined. A separate grade from 0 to 3 was calculated depending on the presence or absence of each variable (absence $=0$; presence up to one third of the field $=1$; presence up to two thirds of the field $=2$; presence over two thirds of the field $=3$ ).

For quantitative histopathology of fibrosis, a numerical fibrotic scale (Ashcroft score) was used [18]. The severity of the fibrotic changes in each lung section was assessed as a mean score of se- 
verity from the observed microscopic fields. More than 40 fields covering each whole lung section were examined at a magnification of 100 in each field. The severity of the fibrotic changes was assessed and allotted a score from 0 to 8 , using the predetermined scale of severity (normal lung $=0$; minimal fibrous thickening of alveolar or bronchiolar walls $=1$; moderate thickening of walls without obvious damage to lung architecture $=3$; increased fibrosis with definite damage to lung structure and formation of fibrous bands or small fibrous masses $=5$; severe distortion of structure and large fibrous areas $=7$; total fibrous obliteration of the field $=8$ ). After examination of the whole fields of each section, the mean of the scores from all fields was taken as the fibrotic score. To prevent observer bias, all histological specimens were numbered randomly and interpreted in a blinded fashion.

\section{Hydroxyproline Analysis}

Sixty-milligram aliquots of lung tissue from each mouse were used for the hydroxyproline assays. A sample of lung homogenate was added to $250 \mu \mathrm{l}$ of $12 \mathrm{~N} \mathrm{HCl}$ for $16 \mathrm{~h}$ at $110^{\circ} \mathrm{C}$. Following centrifugation, $25 \mu \mathrm{l}$ of each supernatant was assayed. To a $25-\mu \mathrm{l}$ sample of the digested lung $25 \mu$ l of citrate/acetate buffer (5\% citric acid, $7.2 \%$ sodium acetate, $3.4 \%$ sodium hydroxide and $1.2 \%$ glacial acetic acid) and $500 \mu \mathrm{l}$ of chloramine-T solution $(1.41 \mathrm{~g}$ chloramine-T, $26 \mathrm{ml} \mathrm{n}$-propanol, $20.7 \mathrm{ml}$ distilled water and 53.3 $\mathrm{ml}$ citrate/acetate buffer) were added. The resulting samples were then incubated at room temperature for $20 \mathrm{~min}$ before $500 \mu \mathrm{l}$ of Ehrlich's solution (4.5 g $\rho$-dimethylaminobenzaldehyde, $18.6 \mathrm{ml}$ n-propanol and $7.8 \mathrm{ml} 70 \%$ perchloric acid) were added. These samples were incubated for $15 \mathrm{~min}$ at $65^{\circ} \mathrm{C}$ and cooled samples were read at $550 \mathrm{~nm}$ in a spectrophotometer. Hydroxyproline concentrations were calculated from a standard curve.

\section{Western Blotting}

Separated lung tissues snap frozen in liquid nitrogen were disrupted using a polytron homogenizer (Tissue Tearor ${ }^{\mathrm{TM}}$; Biospec Products Inc., Bartlesville, Okla., USA) and centrifuged. Proteins were purified from the supernatant and the concentration was assessed using the Bradford method. Protein samples were separated by $8-5 \%$ sodium dodecyl sulfate polyacrylamide gel electrophoresis and transferred to a polyvinylidene difluoride membrane (Amersham Pharmacia Biotech, Buckinghamshire, UK). After blocking with $10 \%$ skim milk (Difco, BD, Franklin Lakes, N.J., USA) for $15 \mathrm{~min}$, the membrane was incubated overnight with a primary antibody at $4^{\circ} \mathrm{C}$. The membrane was washed 3 times with PBS and incubated with a secondary antibody for $1 \mathrm{~h}$ at room temperature. Horseradish peroxidase-conjugated IgG in $5 \%$ skim milk $(1: 1,000)$ was used as the secondary antibody. The target protein was detected using the ECL Western Blotting Analysis System (Amersham Pharmacia Biotech, Piscataway, N.J., USA) and X-ray film. The expression levels of anti-TGF- $\beta 1$ antibody (1:200; Santa Cruz Biotechnology, Santa Cruz, Calif., USA), anti-PDGFR- $\beta$ antibody (1:200; Santa Cruz), anti-phosphorylated (p)Smad2 (1:1,000; Cell Signaling Technology, Beverly, Mass., USA), anti-pSmad3 (1:1,000; Cell Signaling Technology), antiSmad7 (1:200; Santa Cruz) and anti- $\beta$-actin antibody (1:5,000; Sigma-Aldrich) were measured.

\section{Real-Time Polymerase Chain Reaction}

For quantitative real-time reverse transcription polymerase chain reaction (RT-PCR) analysis of the expression of genes en- coding TGF- $\beta 1$ and PDGF, total RNA was isolated from lung homogenates using Trizol (Gibco-BRL, Gaithersburg, Md., USA) and reverse transcribed. Each PCR cycle was performed in a final volume of $25 \mu \mathrm{l}(2 \mu \mathrm{l}$ of cDNA, $0.2 \mu \mathrm{mol} / \mathrm{l}$ of both forward and reverse primers, $1.5 \mathrm{~mol} / 1 \mathrm{MgCl}_{2}, 0.12 \mu \mathrm{mol} / \mathrm{l} \mathrm{TaqMan}$ probe and $180 \mu \mathrm{mol} / \mathrm{l} \mathrm{dNTP}$ in $1 \mathrm{M}$ PCR Gold buffer). Primer sequences used in the present study were as follows: TGF- $\beta 1$, forward $5^{\prime}$ GCAACATCAAAAGACAGCCACTCA-3' and reverse 5'-GACGTCAAAAGACAGCCACTCA-3'; PDGF, forward 5'-CCTGA-

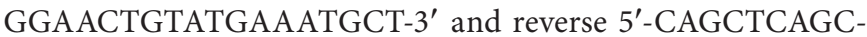
CCCATCTTC-3'; GAPDH (housekeeping control), forward 5'-ACCCAGAAGACTGTGGATGG-3' and reverse 5'-TGTGAGGGAGATGCTCAGTG-3'. The fluorescence emitted by the reporter dye was detected in real time and the threshold cycle $\left(\mathrm{C}_{\mathrm{T}}\right)$ of each sample was recorded as a measure of the amount of PCR product in the sample [19]. The $\mathrm{C}_{\mathrm{T}}$ is the fraction cycle number at which the fluorescence generated by the reporter dye exceeds a set level above baseline. When indicated, the target signal was normalized against the relative quantity of GAPDH and expressed as $\Delta \mathrm{C}_{\mathrm{T}}=\mathrm{C}_{\mathrm{T} \text {,target }}-\mathrm{C}_{\mathrm{T}, \mathrm{GAPDH}}$. The changes in target signal relative to the total amount of genomic DNA were expressed as $\Delta \Delta \mathrm{C}_{\mathrm{T}}=\Delta \mathrm{C}_{\mathrm{T} \text {,treatment }}-\Delta \mathrm{C}_{\mathrm{T} \text {,control. }}$. Relative changes in metastasis were then calculated as $2^{-\Delta \Delta \mathrm{CT}}$.

\section{Proliferation Assay}

Cell proliferation was quantified by the colorimetric XTTbased assay kit (Boehringer Mannheim, Mannheim, Germany). A lung fibroblast cell line (HFL-1) was obtained from the American Type Culture Collection (No. CCL-153; Rockville, Md., USA). Cells were seeded on 96-well microtiter plates (Greiner, Frickenhausen, Germany) at a concentration of $5 \times 10^{3}$ cells $/ \mathrm{ml}$. Cells were incubated in Dulbecco's modified Eagle's medium containing $10 \%$ fetal bovine serum and $1 \%$ penicillin-streptomycin at $37^{\circ} \mathrm{C}$ in a humidified atmosphere of $5 \% \mathrm{CO}_{2}$ for $24 \mathrm{~h}$, then serum starved for $24 \mathrm{~h}$. Imatinib or nilotinib at various concentrations were co-administered with PDGF-AA or PDGF-BB (20 ng/ml) and cells were incubated for $72 \mathrm{~h}$. Then, $50 \mu \mathrm{l}$ XTT solution was added for $4 \mathrm{~h}$ at $37^{\circ} \mathrm{C}$. Absorbance was measured at $450 \mathrm{~nm}$ in a Dynatech MR 3.13 Microelisa Reader (Dynex Technologies, Ashford, UK).

\section{Data Analysis}

Results from each group were compared using the MannWhitney nonparametric $U$ test. All statistical analyses were performed using SPSS version 15.0 software (SPSS Inc., Chicago, Ill., USA). All results are given as the means \pm SEM and $p<0.05$ was considered statistically significant.

\section{Results}

\section{Effect of Imatinib and Nilotinib on Histopathology}

Histopathology of lung specimens demonstrated that bleomycin stimulation induced damage to alveolar epithelial cells in mice sacrificed on days 3 and 7. Infiltration of inflammatory cells into the interstitium and alveolar space was observed. These morphological changes were less pronounced in the imatinib- or nilotinib-treated 
Control

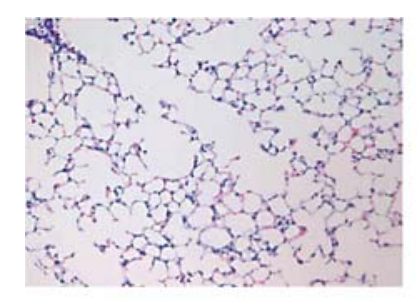

Day 7

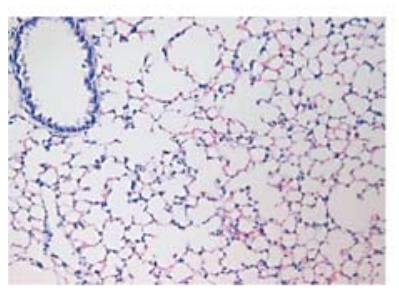

Day 14

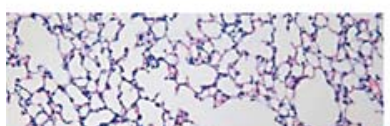

(HE)
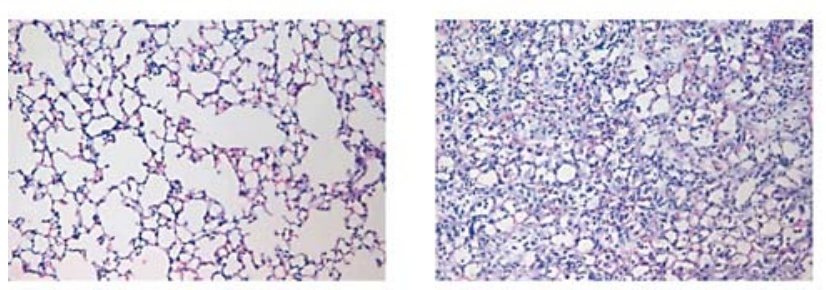

Day 14

(MT)

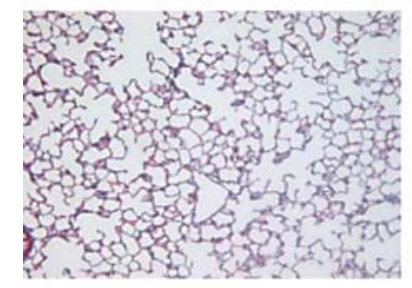

Day 21

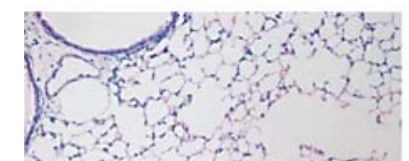

(HE)

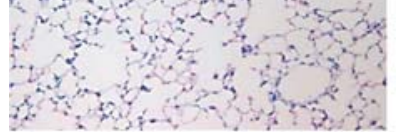

Day 21

(MT)

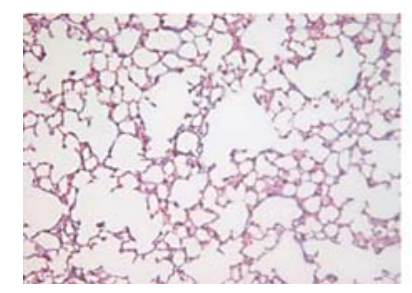

BLM
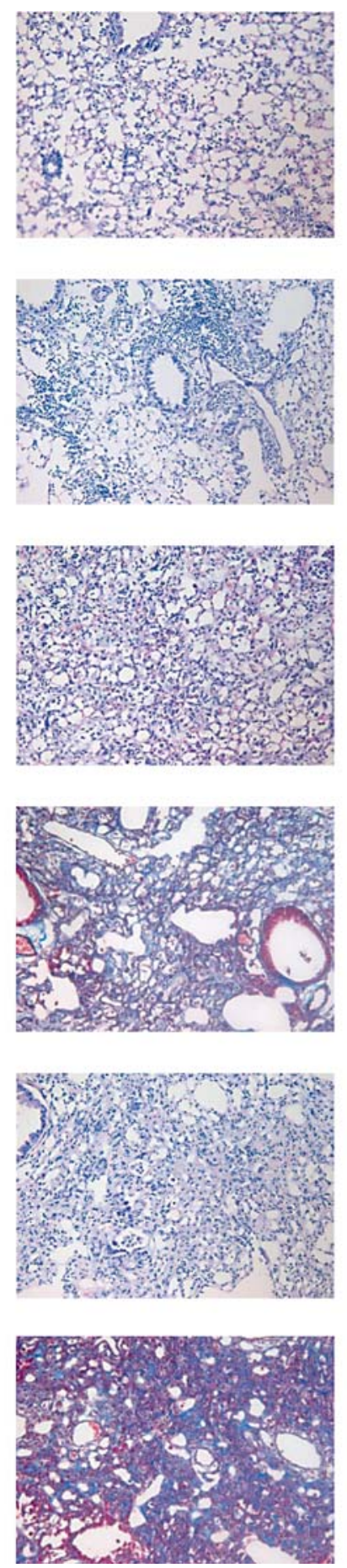

$\mathrm{BLM}+\mathrm{I}$
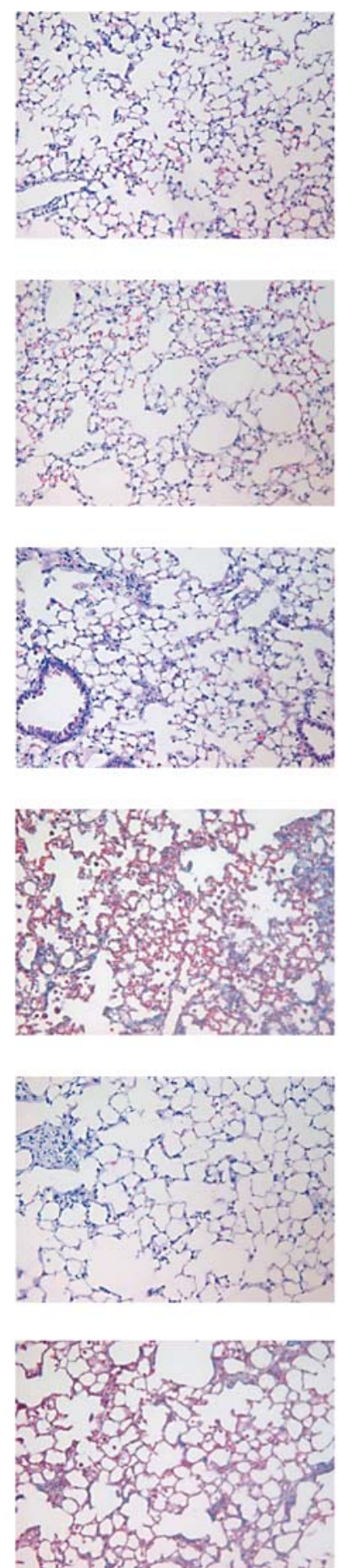

$\mathrm{BLM}+\mathrm{N}$
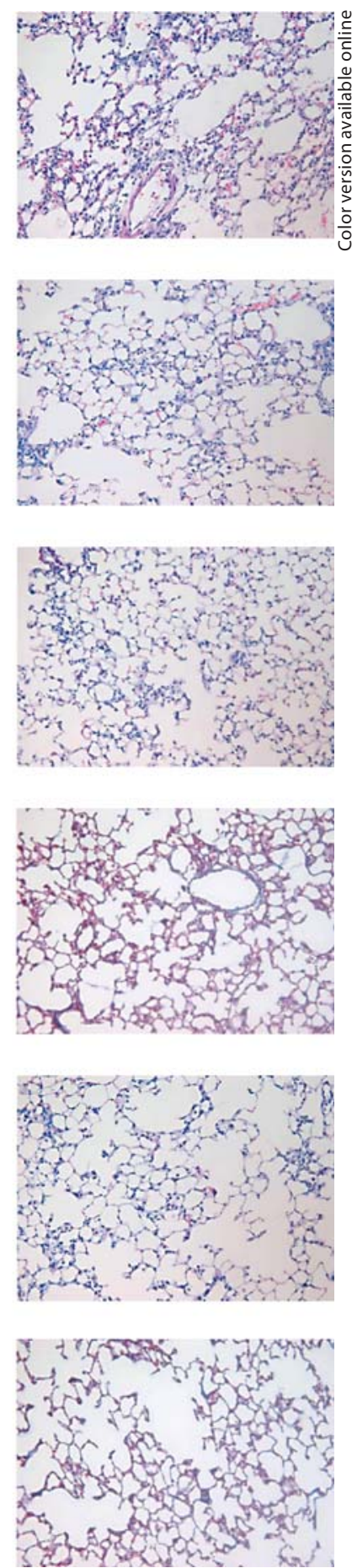

Fig. 1. Representative histological lung sections from each group (R 200). Tissues were fixed in 4\% paraformaldehyde and stained with hematoxylin and eosin. Intratracheal administration of bleomycin induced lung injury with infiltration of inflammatory cells on days 3 and 7, and induced pulmonary fibrosis with depo- sition of collagen on days 14 and 21 . These changes were attenuated by the treatment with imatinib or nilotinib. BLM = Bleomycin; $\mathrm{BLM}+\mathrm{I}=$ bleomycin plus imatinib; $\mathrm{BLM}+\mathrm{N}=$ bleomycin plus nilotinib; $\mathrm{HE}=$ hematoxylin and eosin; $\mathrm{MT}=$ Masson's trichrome. 


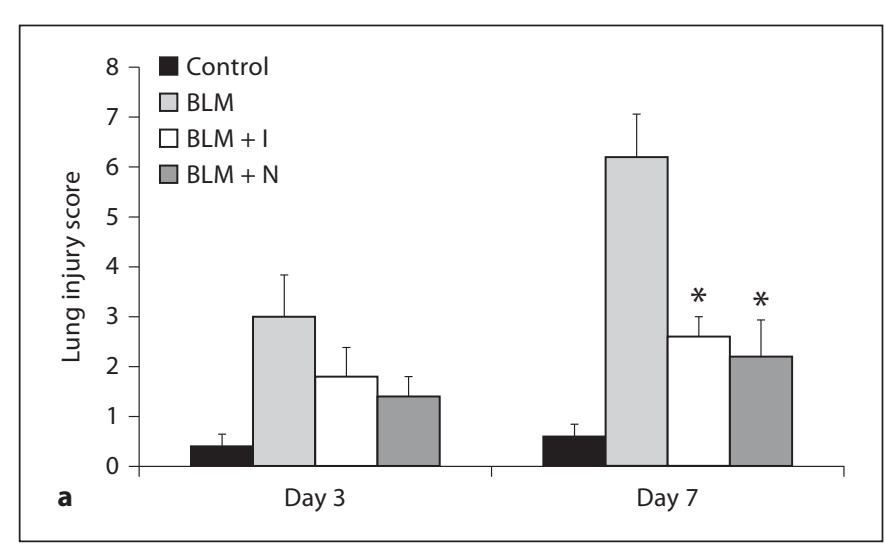

Fig. 2. Quantitative examination of the effects of imatinib and nilotinib on bleomycin-induced lung injury (a) and pulmonary fibrosis (b). Compared with bleomycin treatment alone, the lung injury score was significantly lower in the imatinib or nilotinib treatment groups on day 7. The Ashcroft score was sig-

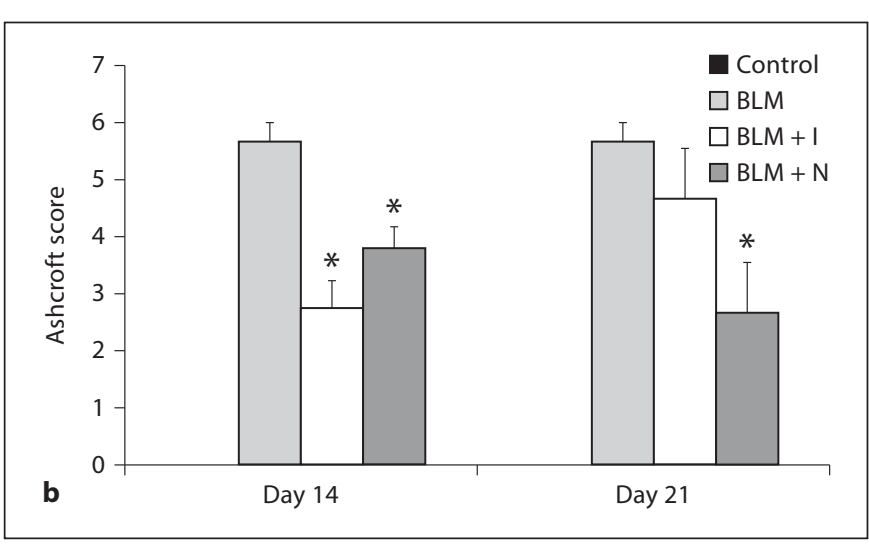

nificantly lower in the imatinib treatment group on day 14 and in the nilotinib treatment group on days 14 and 21 . The number of mice analyzed in each group ranged from 3 to 5 . Abbreviations are as in figure $1 .{ }^{*} \mathrm{p}<0.05$ for BLM vs. BLM + I or for BLM vs. BLM + N. groups. Bleomycin induced fibrotic changes in mice sacrificed on days 14 and 21, and these changes were attenuated by imatinib or nilotinib treatment (fig. 1). Bleomycin-treated mice sacrificed on days 14 and 21 showed deposition of collagen with destruction of normal tissue architecture, consistent with the final fibrotic stage of bleomycin-induced lung fibrosis [20]. However, bleomycin-treated mice given imatinib or nilotinib demonstrated less collagen deposition and tissue destruction as shown with both hematoxylin and eosin as well as Masson's trichrome staining (fig. 1). Quantitative histology demonstrated that the lung injury scores in the imatinib and nilotinib treatment groups were significantly lower than in the bleomycin alone group on day $7(2.60 \pm 0.40$ for imatinib vs. $6.20 \pm 0.86$ for bleomycin, $p<0.05 ; 2.20$ \pm 0.73 for nilotinib vs. $6.20 \pm 0.86$ for bleomycin, $\mathrm{p}<$ 0.05; fig. 2a). The Ashcroft scores in the imatinib and nilotinib treatment groups were also significantly lower than in the bleomycin alone group on day $14(2.75 \pm 0.48$ for imatinib vs. $5.67 \pm 0.33$ for bleomycin, $p<0.05 ; 3.80$ \pm 0.37 for nilotinib vs. $5.67 \pm 0.33$ for bleomycin, $\mathrm{p}<$ 0.05 ) and the score in the nilotinib treatment group was significantly lower than in the bleomycin only group on day 21 (2.67 \pm 0.88 for nilotinib vs. $5.67 \pm 0.33$ for bleomycin, $\mathrm{p}<0.05$; fig. $2 \mathrm{~b}$ ).

\section{Effect of Imatinib and Nilotinib on Inflammatory}

Cells and Inflammatory Cytokines

Intratracheal bleomycin administration induced a significant increase in the numbers of inflammatory cells.
Imatinib or nilotinib treatments significantly reduced the number of inflammatory cells in BAL fluid (table 1). Intratracheal bleomycin administration induced a significant increase in the levels of IL-6, IL-1 $\beta$ and TNF- $\alpha$ in BAL fluid (all measured in $\mathrm{pg} / \mathrm{ml}$ ). Imatinib treatment significantly reduced the levels of IL- 6 on day 3 (137.28 \pm 47.91 for imatinib vs. $217.25 \pm 61.75$ for bleomycin, $\mathrm{p}<0.05)$ and day $7(78.89 \pm 28.92$ vs. $617.41 \pm 107.71$, $\mathrm{p}<0.05)$. Nilotinib treatment also significantly reduced the levels of IL- 6 on day 7 ( $23.69 \pm 1.85$ for nilotinib vs. $617.41 \pm 107.71$ for bleomycin, $\mathrm{p}<0.01)$, day 14 (38.78 \pm 8.80 vs. $388.87 \pm 90.53, \mathrm{p}<0.05)$ and day $21(17.98 \pm$ 1.58 vs. $72.59 \pm 11.41, p<0.01)$. Imatinib treatment significantly reduced the level of IL- $1 \beta$ on day $3(6.81 \pm 1.22$ $\mathrm{pg} / \mathrm{ml}$ for imatinib vs. $20.70 \pm 4.12$ for bleomycin, $\mathrm{p}<$ $0.05)$ and day $7(9.48 \pm 3.90$ vs. $19.12 \pm 3.95, \mathrm{p}<0.05)$. Nilotinib treatment also significantly reduced the level of IL-1 $\beta$ on day $7(0.42 \pm 0.22$ for nilotinib vs. $19.12 \pm 3.95$ for bleomycin, $p<0.05)$. Nilotinib treatment significantly reduced the level of TNF- $\alpha$ on day $7(16.95 \pm 3.07$ for nilotinib vs. $45.38 \pm 12.34$ for bleomycin, $\mathrm{p}<0.05$; fig. 3 ).

\section{Effects of Imatinib and Nilotinib on the Levels of}

Hydroxyproline and TGF- $\beta 1$

Collagen deposition was assessed by measuring the hydroxyproline content in lung tissues (all measured in $\mu \mathrm{g} /$ lung). Bleomycin administration induced a significant increase in the level of hydroxyproline. Imatinib treatment significantly reduced the level of hydroxyproline on day 21 (1.44 \pm 0.11 for imatinib vs. $7.74 \pm 2.17$ for bleomycin, 
Fig. 3. Effects of imatinib and nilotinib treatments on inflammatory cytokines. The levels of IL- 6 (a), IL-1 $\beta$ (b) and TNF- $\alpha$ (c) were measured in BAL fluid. Intratracheal administration of bleomycin induced increased levels of IL-6, IL-1 $\beta$ and TNF- $\alpha$. Compared with the bleomycin treatment group, the level of IL- 6 was significantly lower in the imatinib treatment group on days 3 and 7 and in the nilotinib treatment group on days 7, 14 and 21 . The level of IL-1 $\beta$ was significantly lower in the imatinib treatment group on days 3 and 7 and in the nilotinib treatment group on day 7. The level of TNF- $\alpha$ was significantly lower in the nilotinib treatment group on day 7. The numbers of mice analyzed in each group ranged from 3 to 5 . Abbreviations are as in figure $1 .{ }^{*} \mathrm{p}<0.05$ for BLM vs. BLM + I or for BLM vs. BLM + N; ${ }^{* *} \mathrm{p}<0.01$ for BLM vs. BLM + I or for BLM vs. $\mathrm{BLM}+\mathrm{N}$.

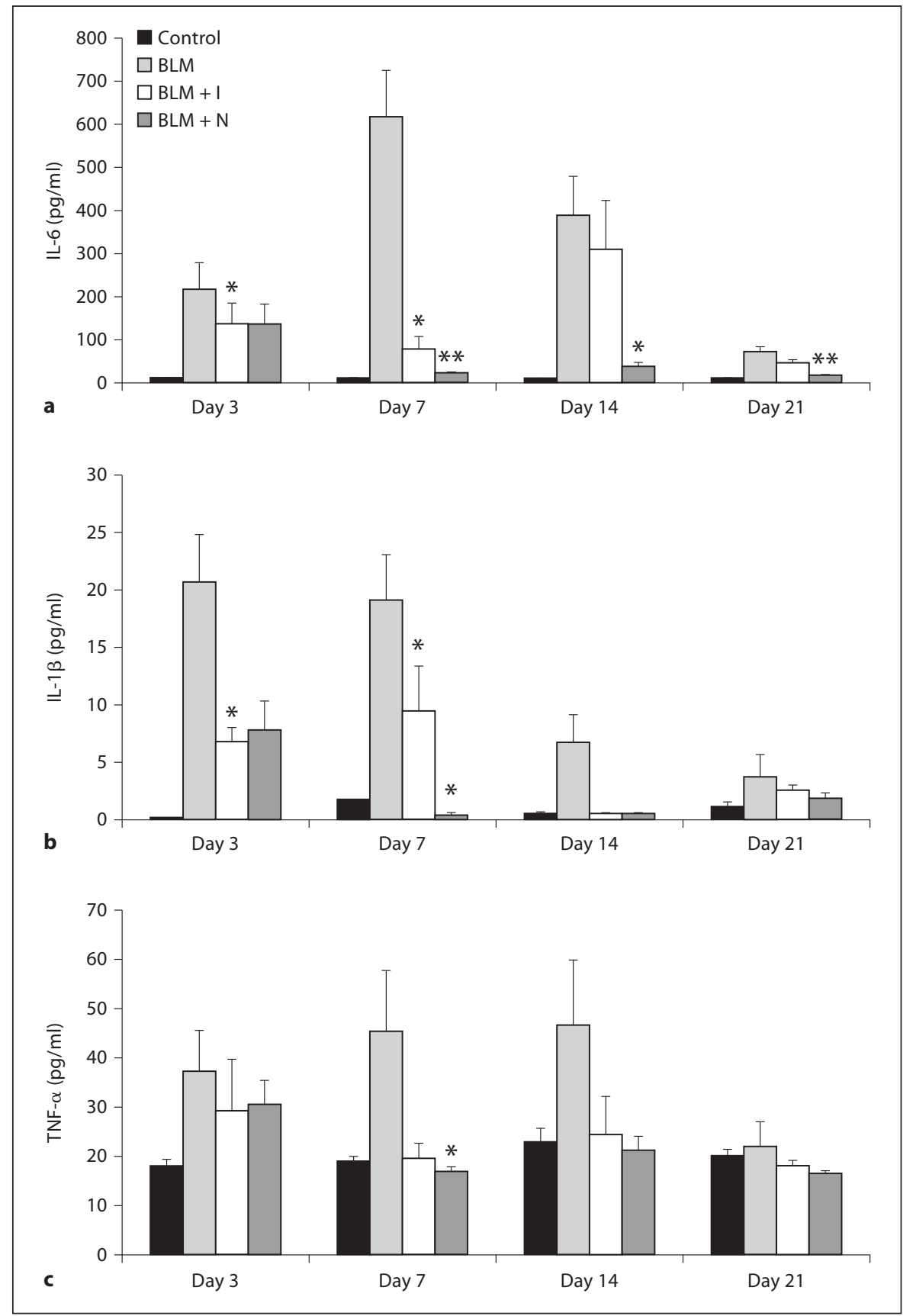

$\mathrm{p}<0.01)$. Nilotinib treatment significantly reduced the levels on day 7 (1.22 \pm 0.23 for nilotinib vs. $2.05 \pm 0.19$ for bleomycin, $\mathrm{p}<0.05)$, day $14(0.86 \pm 0.13$ vs. $2.10 \pm$ $0.30, \mathrm{p}<0.01)$ and day $21(2.64 \pm 0.38$ vs. $7.74 \pm 2.17$, $\mathrm{p}<0.05$; fig. 4a). The level of TGF- $\beta 1$ was measured in lung tissue by ELISA (measured in $\mathrm{pg} / \mathrm{ml}$ ). Bleomycin administration induced a significant increase in the level of TGF- $\beta 1$. Imatinib treatment significantly reduced the lev- el of TGF- $\beta 1$ on day $3(1,658.06 \pm 88.06$ for imatinib vs. $2,118.65 \pm 59.31$ for bleomycin, $\mathrm{p}<0.05)$ and day 21 $(2,069.53 \pm 59.35$ vs. $2,507.89 \pm 107.62, \mathrm{p}<0.05)$. Nilotinib treatment also significantly reduced the levels of TGF- $\beta 1$ on day $3(1,464.80 \pm 156.29$ for niloti-nib vs. $2,118.65 \pm 59.31$ for bleomycin, $\mathrm{p}<0.01)$, day $14(1,333.83$ \pm 159.95 vs. $2,549.32 \pm 380.73, \mathrm{p}<0.01)$ and day 21 $(1,698.27 \pm 148.27$ vs. $2,507.89 \pm 107.62, \mathrm{p}<0.01$; fig. $4 \mathrm{~b})$. 
Fig. 4. Effects of imatinib and nilotinib on the levels of hydroxyproline and TGF- $\beta 1$. Compared with the bleomycin treatment group, the level of hydroxyproline was significantly lower in the imatinib treatment group on day 21 and in the nilotinib treatment group on days 7, 14 and 21. The level of TGF- $\beta 1$ was significantly lower in the imatinib treatment group on days 3 and 21 and in the nilotinib treatment group on days 3, 14 and 21. The levels of hydroxyproline (a) and TGF- $\beta 1$ (b) were measured in lung tissue. The number of mice analyzed in each group ranged from 3 to 5 . Abbreviations are as in figure $1 .{ }^{*} \mathrm{p}<0.05$ for $B L M$ vs. BLM + I or for BLM vs. BLM + N; ** $p<0.01$ for BLM vs. BLM + I or for BLM vs. $\mathrm{BLM}+\mathrm{N}$.

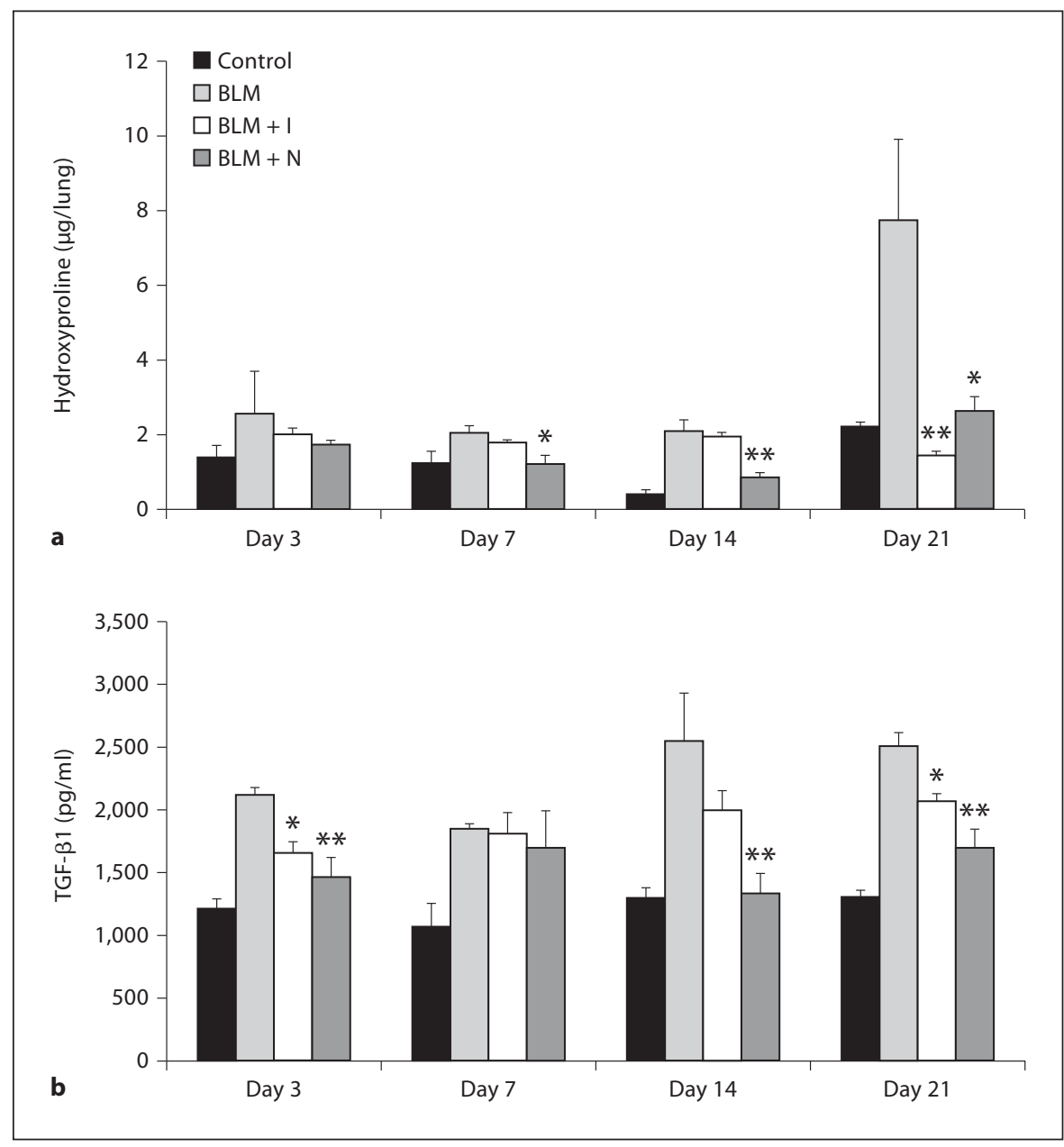

Table 1. Results of BAL fluid analysis $\left(\times 10^{4} / \mathrm{ml}\right)$ for the 4 groups of mice on days 3,7 , 14 and 21

\begin{tabular}{|c|c|c|c|c|c|c|c|c|}
\hline & \multicolumn{4}{|l|}{ Day 3} & \multicolumn{4}{|l|}{ Day 7} \\
\hline & Control & BLM & BLM + I & $\mathrm{BLM}+\mathrm{N}$ & Control & BLM & $\mathrm{BLM}+\mathrm{I}$ & $\mathrm{BLM}+\mathrm{N}$ \\
\hline Total cells & $11.20 \pm 1.31$ & $78.00 \pm 14.01$ & $49.80 \pm 6.94$ & $16.00 \pm 2.94^{* *}$ & $18.40 \pm 0.81$ & $307.60 \pm 45.10$ & $114.60 \pm 11.39^{* *}$ & $65.20 \pm 7.02^{* *}$ \\
\hline Macrophages & $11.08 \pm 1.30$ & $46.16 \pm 5.85$ & $35.24 \pm 4.97$ & $12.72 \pm 2.42^{* *}$ & $18.18 \pm 0.77$ & $138.30 \pm 19.06$ & $85.12 \pm 17.26$ & $53.70 \pm 5.66^{* *}$ \\
\hline Lymphocytes & $0.06 \pm 0.02$ & $9.56 \pm 1.27$ & $4.62 \pm 0.48^{* *}$ & $1.27 \pm 0.26^{* *}$ & $0.16 \pm 0.04$ & $51.08 \pm 8.23$ & $9.22 \pm 1.88^{* *}$ & $3.80 \pm 0.74^{* *}$ \\
\hline Neutrophils & $0.00 \pm 0.00$ & $21.88 \pm 12.31$ & $9.84 \pm 2.99$ & $1.90 \pm 0.50$ & $0.06 \pm 0.04$ & $115.70 \pm 45.72$ & $20.18 \pm 8.50^{*}$ & $7.42 \pm 1.41^{*}$ \\
\hline \multirow[t]{3}{*}{ Eosinophils } & $0.00 \pm 0.00$ & $0.42 \pm 0.10$ & $0.12 \pm 0.07^{* *}$ & $0.07 \pm 0.02^{* *}$ & $0.00 \pm 0.00$ & $2.52 \pm 0.66$ & $0.08 \pm 0.08^{* *}$ & $0.26 \pm 0.09^{* *}$ \\
\hline & \multicolumn{4}{|l|}{ Day 14} & \multicolumn{4}{|l|}{ Day 21} \\
\hline & Control & BLM & BLM + I & $\mathrm{BLM}+\mathrm{N}$ & Control & BLM & BLM + I & $\mathrm{BLM}+\mathrm{N}$ \\
\hline Total cells & $21.60 \pm 2.01$ & $194.60 \pm 17.97$ & $147.25 \pm 23.38$ & $88.80 \pm 4.06^{* *}$ & $16.80 \pm 0.12$ & $187.00 \pm 42.29$ & $113.66 \pm 12.41$ & $43.66 \pm 6.76^{*}$ \\
\hline Macrophages & $21.32 \pm 1.96$ & $101.83 \pm 13.90$ & $122.70 \pm 25.21$ & $82.18 \pm 4.18$ & $16.68 \pm 3.09$ & $128.06 \pm 9.21$ & $93.06 \pm 9.39^{*}$ & $41.30 \pm 5.18^{* *}$ \\
\hline Lymphocytes & $0.18 \pm 0.04$ & $71.30 \pm 25.38$ & $17.97 \pm 8.96^{* *}$ & $2.58 \pm 0.30^{* *}$ & $0.08 \pm 0.03$ & $50.66 \pm 31.88$ & $14.90 \pm 3.21$ & $1.76 \pm 1.12$ \\
\hline Neutrophils & $0.12 \pm 0.03$ & $20.16 \pm 6.66$ & $6.05 \pm 4.28^{*}$ & $3.96 \pm 0.81^{* *}$ & $0.02 \pm 0.02$ & $6.80 \pm 3.05$ & $4.43 \pm 0.08$ & $0.53 \pm 0.43^{*}$ \\
\hline Eosinophils & $0.00 \pm 0.00$ & $1.36 \pm 0.48$ & $0.47 \pm 0.35$ & $0.08 \pm 0.04^{* *}$ & $0.00 \pm 0.00$ & $1.43 \pm 0.69$ & $1.30 \pm 0.34$ & $0.06 \pm 0.06^{*}$ \\
\hline
\end{tabular}

$\mathrm{BLM}=$ Bleomycin; $\mathrm{BLM}+\mathrm{I}=$ bleomycin plus imatinib; $\mathrm{BLM}+\mathrm{N}=$ bleomycin plus nilotinib. ${ }^{*} \mathrm{p}<0.05$ for BLM vs. BLM+I or for BLM vs. BLM+N; ${ }^{* *} \mathrm{p}<0.01$ for BLM vs. BLM+I or for BLM vs. BLM+N ( $\mathrm{n}=3-5$ for each group). 
Fig. 5. Effects of imatinib and nilotinib treatments on the expression of TGF- $\beta 1$ (a) and PDGFR- $\beta$ (b). Compared with the bleomycin treatment group, the expression of TGF- $\beta 1$ was significantly lower in the imatinib and nilotinib treatment groups on days $3,7,14$ and 21 . The expression of PDGFR- $\beta$ was also significantly lower in the imatinib treatment group on days 3, 7 and 21 and in the nilotinib treatment group on days 3, 7, 14 and 21. Data are representative of 3 separate experiments. Abbreviations are as in figure 1 , or as follows: Con = control; $\mathrm{B}+\mathrm{I}=$ bleomycin plus imatinib; $\mathrm{B}+\mathrm{N}=$ bleomycin plus nilotinib. ${ }^{*} \mathrm{p}<0.05$ for BLM vs. BLM + I or for BLM vs. BLM + N; ${ }^{* *} \mathrm{p}<0.01$ for BLM vs. BLM + I or for BLM vs. BLM $+\mathrm{N}$.

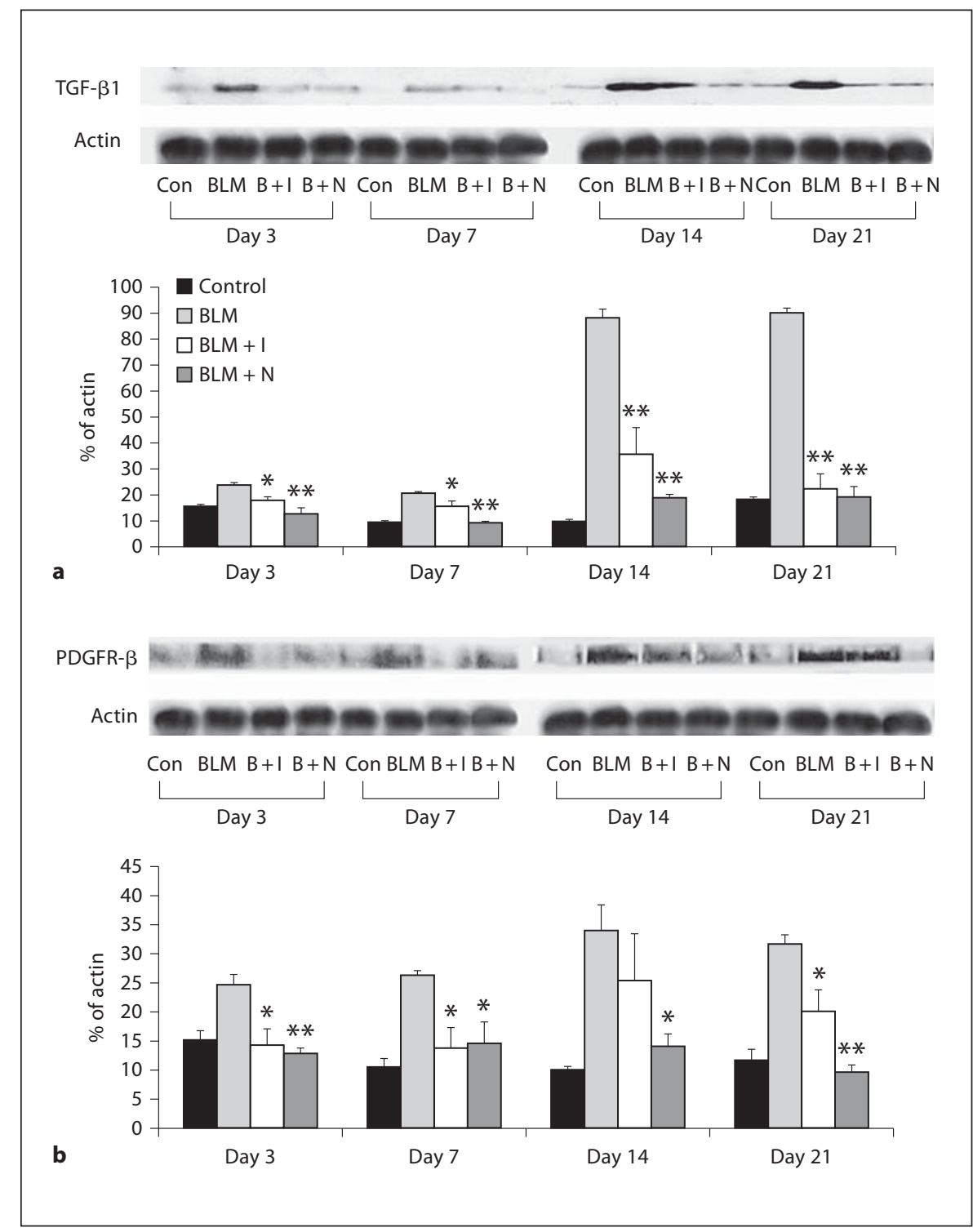

Effects of Imatinib and Nilotinib on the Expression Levels of TGF- $\beta 1, P D G F R-\beta, p S m a d 2, p S m a d 3$ and Smad7

The expression levels of TGF- $\beta 1$ and PDGFR- $\beta$ were increased by bleomycin administration. Imatinib and nilotinib treatments significantly reduced the expression of TGF- $\beta 1$ on days 3, 7, 14 and 21 (fig. $5 \mathrm{a}$ ). Imatinib treatment significantly reduced the expression of PDGFR- $\beta$ on days 3, 7 and 21. Nilotinib treatment significantly reduced the expression of PDGFR- $\beta$ on days 3, 7, 14 and 21 (fig. 5b). The expression levels of pSmad 2 and $\mathrm{pSmad} 3$ were increased by bleomycin administration, and nilotinib treatment significantly reduced the expression lev- els of pSmad 2 and pSmad 3 on days 14 and 21 . The expression of Smad7 was decreased by bleomycin administration and nilotinib treatment significantly increased the expression of Smad7 on day 21 (fig. 6).

\section{Effect of Imatinib and Nilotinib on the Expression of}

Genes Encoding TGF- $\beta 1$ and PDGF

The expression levels of genes encoding TGF- $\beta 1$ and PDGF were analyzed by real-time RT-PCR. Expression levels of the genes for TGF- $\beta 1$ and PDGF were increased by bleomycin administration, but imatinib treatment significantly reduced the expression of the gene for TGF- $\beta 1$ on days 14 and 21. Imatinib also significantly reduced the 
Fig. 6. Effects of imatinib and nilotinib treatments on the expression of pSmad2, pSmad3 and Smad7. Compared with the bleomycin treatment group, the expression of pSmad 2 and pSmad 3 was significantly lower in the nilotinib treatment group on days 14 and 21. The expression of Smad7 was significantly higher in the nilotinib treatment group on day 21. Data are representative of 3 separate experiments. Abbreviations are as in figures 1 and 5 . ${ }^{*} \mathrm{p}<0.05$ for BLM vs. BLM + I or for BLM vs. $B L M+N$; ${ }^{* *} p<0.01$ for BLM vs. BLM $+\mathrm{I}$ or for BLM vs. BLM $+\mathrm{N}$.

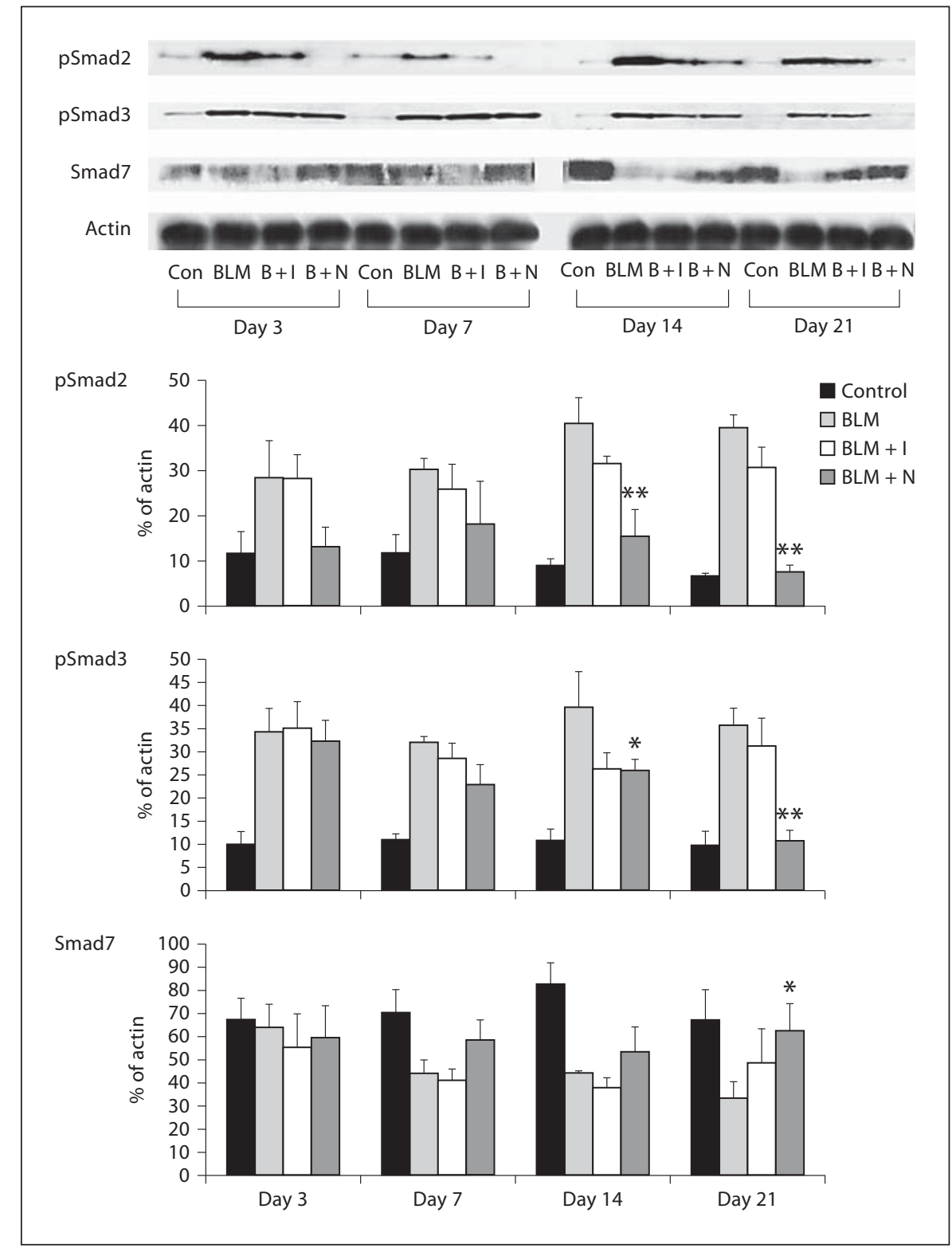

expression of the gene for PDGF on day 14. Nilotinib significantly reduced the expression of the gene for PDGF on days 14 and 21 (fig. 7).

\section{Effects of Imatinib and Nilotinib on the Growth of \\ Lung Fibroblasts Stimulated by PDGF}

As shown in figure 8, both PDGF-AA and PDGF-BB induced proliferation in lung fibroblasts. The addition of imatinib or nilotinib significantly inhibited this cell proliferation. Growth inhibition was observed even when imatinib was used at $0.1 \mu \mathrm{M}$ and nilotinib at $0.03 \mu \mathrm{M}$.

\section{Effects of Imatinib and Nilotinib in a Therapeutic Model}

An additional experiment was performed to clarify the effect of imatinib and nilotinib in a therapeutic model. Imatinib and nilotinib were administered to mice starting at day 7 after bleomycin instillation. Mice were sacrificed on day 21. Intratracheal administration of bleomycin induced pulmonary fibrosis, which was confirmed by the histologic findings and Ashcroft score. Nilotinib treatment significantly reduced the Ashcroft score $(2.00 \pm 0.37$ for nilotinib vs. $3.33 \pm 0.42$ for bleomycin, 


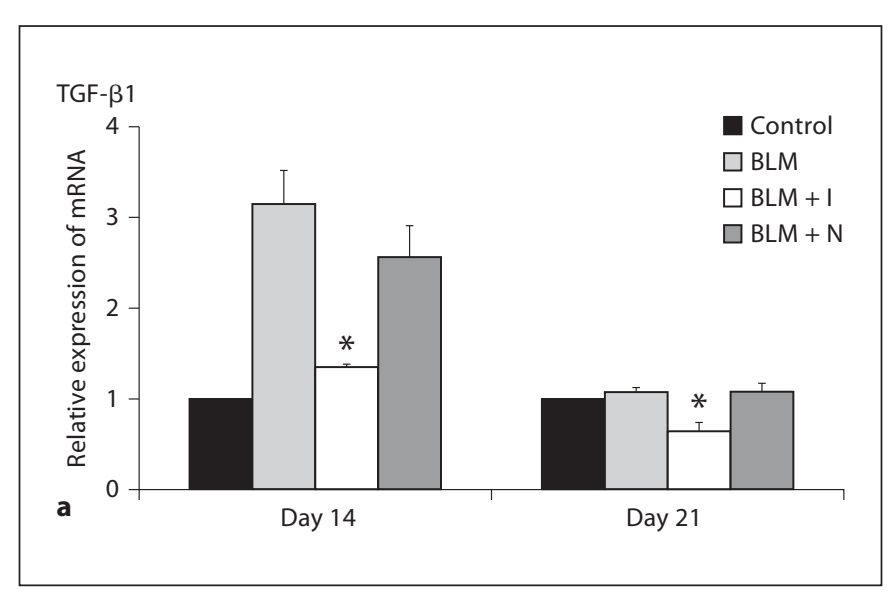

Fig. 7. Effects of imatinib and nilotinib treatments on the expression levels of genes encoding TGF- $\beta 1$ (a) and PDGF (b). Compared with the bleomycin treatment group, the expression levels of the gene encoding TGF- $\beta 1$ were significantly lower in the imatinib treatment group on days 14 and 21 . The expression levels of the gene encoding PDGF were significantly lower in the imatinib

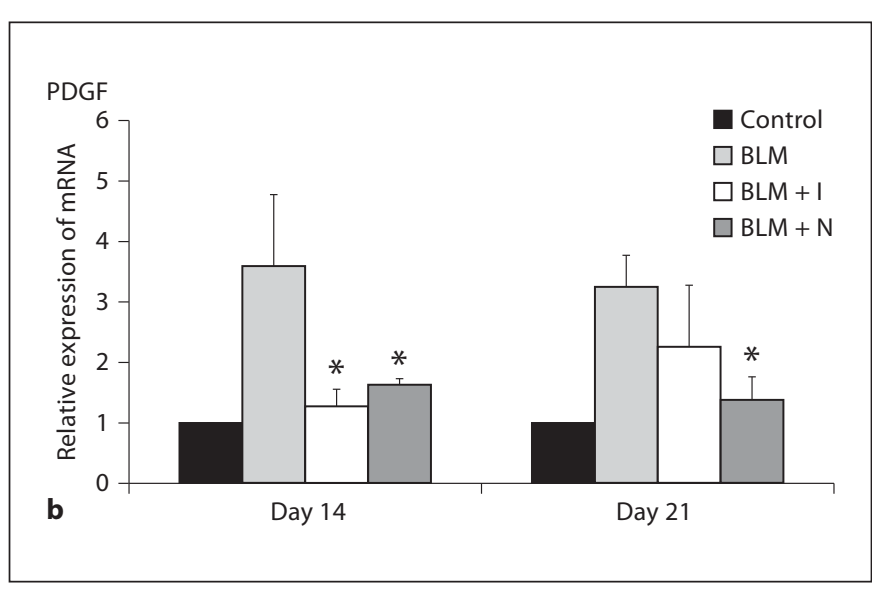

treatment group on day 14 and in the nilotinib treatment group on days 14 and 21. Data are representative of 3 separate experiments. Abbreviations are as in figure $1 .{ }^{*} \mathrm{p}<0.05$ for BLM vs. BLM $+\mathrm{I}$ or for BLM vs. BLM $+\mathrm{N}$; ${ }^{* *} \mathrm{p}<0.01$ for BLM vs. BLM + I or for BLM vs. BLM + N.

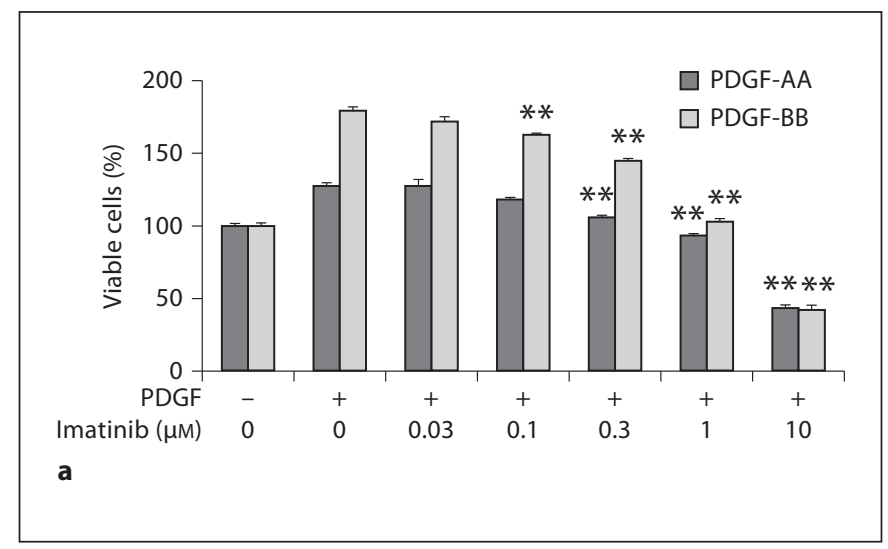

Fig. 8. Effects of imatinib (a) and nilotinib (b) treatments on the growth of lung fibroblasts stimulated by PDGF. Compared with the PDGF-AA or PDGF-BB alone treatment groups, cell proliferation was significantly inhibited by the addition of imatinib or nilotinib. Data are representative of 3 separate experiments. ${ }^{*} \mathrm{p}<$

$\mathrm{p}<0.05$; fig. 9b). However, imatinib failed to reduce the Ashcroft score. Intratracheal bleomycin administration induced a significant increase in the numbers of inflammatory cells. Imatinib or nilotinib treatment showed little effect on the number of inflammatory cells in BAL fluid (fig. 9c). Bleomycin administration induced a significant increase in the level of hydroxyproline. Nilotinib treatment significantly reduced the level of hydroxypro-

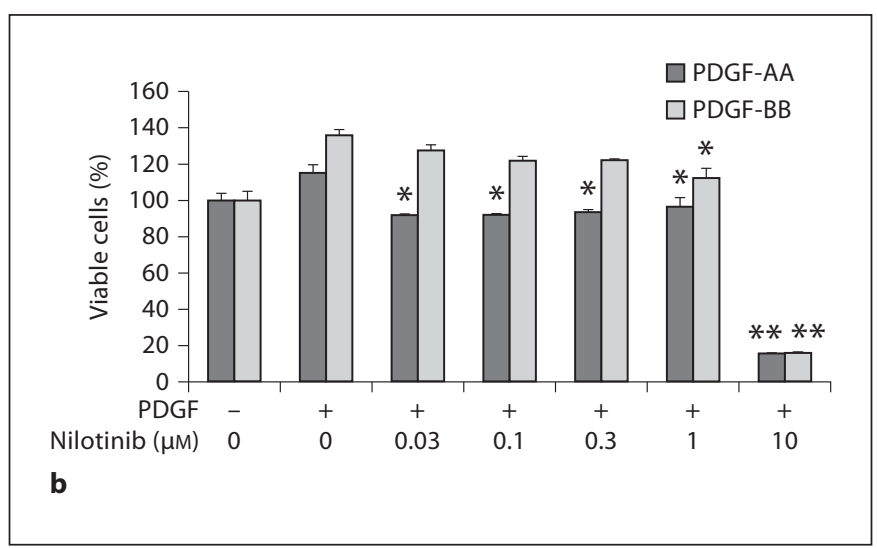

0.05 for groups treated with PDGF-AA or PDGF-BB vs. groups treated with PDGF-AA or PDGF-BB plus imatinib or nilotinib; ${ }^{* *} \mathrm{p}<0.01$ for groups treated with PDGF-AA or PDGF-BB vs. groups treated with PDGF-AA or PDGF-BB plus imatinib or nilotinib. 


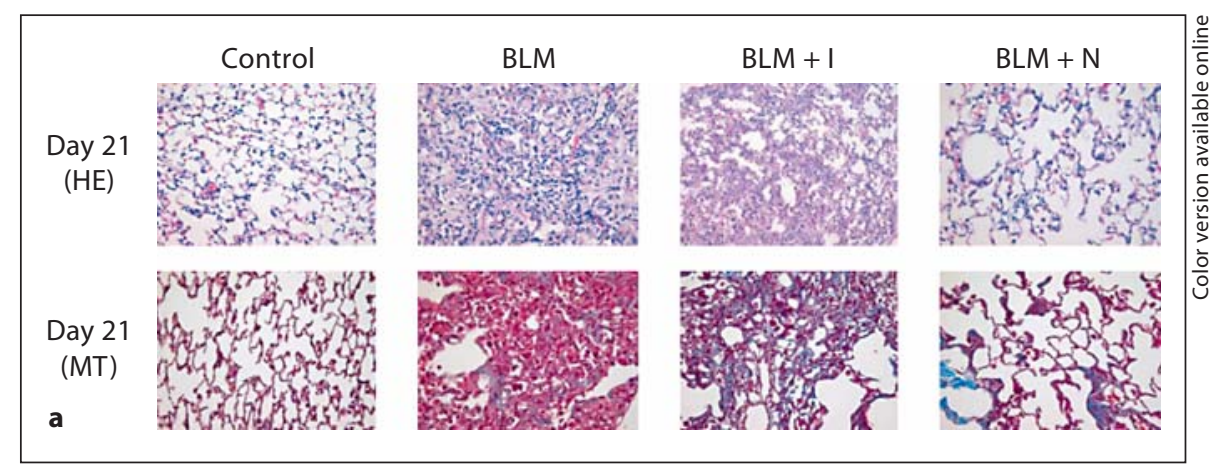

Fig. 9. a Effects of imatinib and nilotinib treatments in a therapeutic model. Representative histological lung sections $(\times 400)$ from each group. b Quantitative examination of the effects of imatinib and nilotinib on bleomycin-induced pulmonary fibrosis. c Results of BAL fluid analysis. Effect of imatinib and nilotinib on the levels of hydroxyproline (d) and TGF- $\beta 1$ (e). Histopathology findings showed that nilotinib treatment attenuated bleomycin-induced pulmonary fibrosis, but imatinib treatment did not. Compared with the group treated with bleomycin alone, the Ashcroft score was significantly lower in the nilotinib treatment group, but not in the imatinib treatment group. Both imatinib and nilotinib treatments had little effect on the numbers of inflammatory cells in BAL fluid. Compared with the bleomycin treatment group, the levels of hydroxyproline and TGF- $\beta 1$ were significantly lower in the nilotinib treatment group, but not in the imatinib treatment group. The number of mice analyzed in each group ranged from 3 to 8 . Abbreviations are as in figure 1. ${ }^{*} \mathrm{p}<0.05$ for BLM vs. BLM + I or for BLM vs. BLM + N.
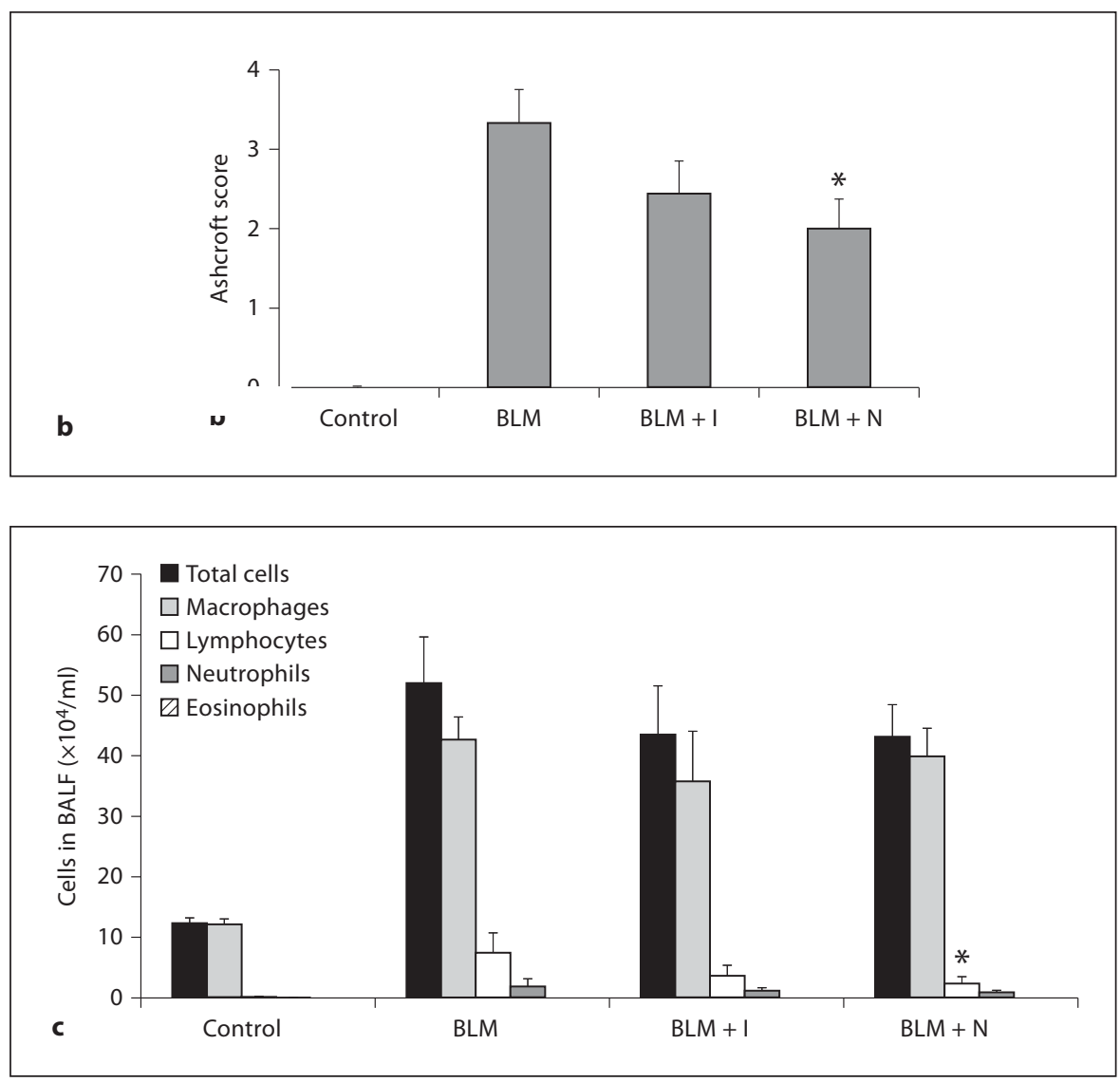

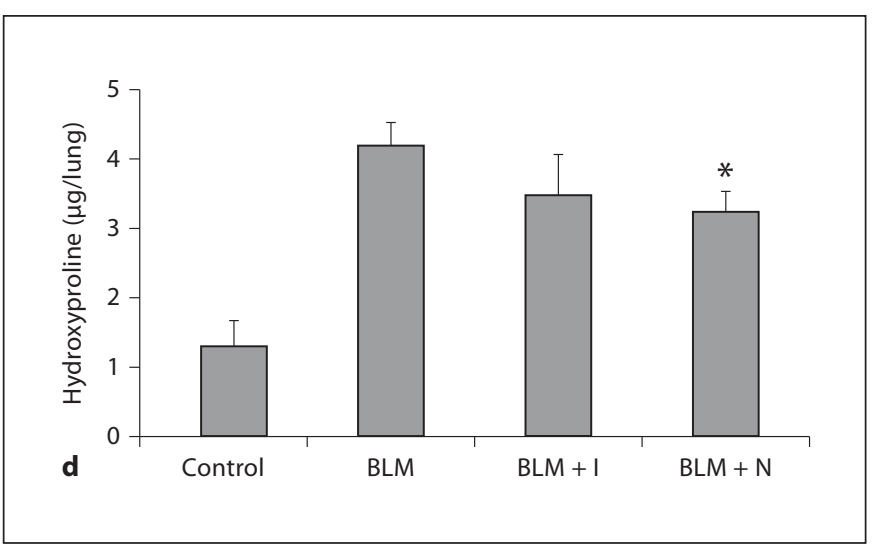

Effect of Nilotinib on Lung Injury and Fibrosis

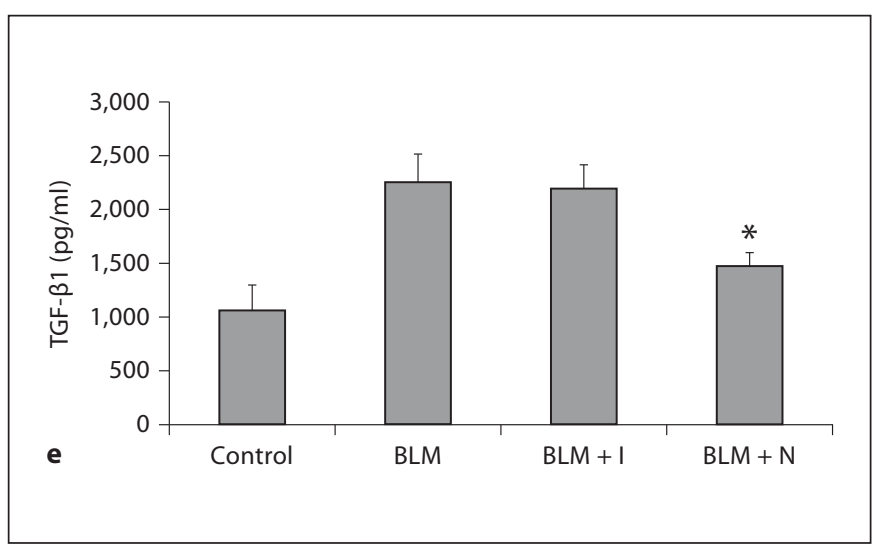




\section{Discussion}

This study was aimed at examining whether imatinib and nilotinib treatment could attenuate ALI and pulmonary fibrosis. Because early inflammatory injury and late fibrosis are the two main pathologies seen in patients with ALI/ARDS, the effects of imatinib and nilotinib were examined in the early inflammatory phase and the late fibrotic phase. In this study, imatinib and nilotinib treatments showed an anti-inflammatory effect during the early phase and an antifibrotic effect during the late phase.

In the bleomycin-induced mouse model of lung injury, the early response is typically characterized by an inflammatory phase when the levels of inflammatory cytokines such as IL-1 $\beta$ and IL- 6 are elevated [21]. The levels of these cytokines increase rapidly within the first 3 days and remain elevated up to day 9 [22]. Then, the development of fibrosis can be seen biochemically and histologically by day 14 with maximal responses generally noted around days 21-28 [23, 24].

In this study, bleomycin induced lung injury in mice sacrificed on days 3 and 7. Imatinib and nilotinib treatments successfully attenuated lung injury, which was confirmed by the histological findings and lung injury scores. These inhibitory effects were associated with the attenuation of inflammatory cell infiltration and reduced levels of cytokines. Thus, imatinib and nilotinib therapy significantly decreased cell counts in the BAL fluid along with the levels of IL- 6 , IL- $1 \beta$ and TNF- $\alpha$. These inhibitory effects were most pronounced on days 3 and 7 .

The anti-inflammatory effect of imatinib has been documented in a few case reports and published experiments. Previous to this study, the anti-inflammatory effects of nilotinib have not been reported. Recent case reports describe that patients with severe rheumatoid arthritis who were treated with imatinib showed marked improvements in disease markers including white blood cell count, C-reactive protein and erythrocyte sedimentation rate [25-27]. Koyama et al. [28] showed that imatinib has both a preventive and therapeutic potential for easing joint inflammation at the effector stage of rheumatoid arthritis. Wolf et al. [29] showed a potent antiinflammatory role of imatinib by modulation of TNF- $\alpha$ and IL-6 production. Our results are compatible with those studies. To our best knowledge, this is the first study showing an anti-inflammatory effect of imatinib and nilotinib on bleomycin-induced lung injury.

If excessive, the fibroproliferative response of ALI/ARDS can be fatal. Fibrosis followed by ALI/ARDS results in impairment of gas exchange and a decrease in lung compli- ance [30]. Martin et al. [31] showed that pulmonary fibrosis is closely related to mortality in patients with established ARDS. In the present study, pulmonary fibrosis was well advanced in the mice sacrificed on days 14 and 21. Imatinib and nilotinib treatments successfully attenuated this pulmonary fibrosis, which was confirmed by the histological findings, Ashcroft score and hydroxyproline assay. These inhibitory effects were associated with reductions in the levels of cytokines associated with pulmonary fibrosis.

PDGF is a growth factor that plays a role in the pathogenesis of pulmonary fibrosis [32,33]. The expression levels of PDGF in epithelial cells and alveolar macrophages were increased in patients with idiopathic pulmonary fibrosis (IPF) [34, 35]. Overexpression of PDGF has also been seen in other forms of lung fibrosis, including bronchiolitis obliterans-organizing pneumonia [36], obliterative bronchiolitis after transplantation [37], histiocytosis $\mathrm{X}$ [38] and coal workers' pneumoconiosis [39]. It is well known that inhibition of the PDGF pathway can attenuate pulmonary fibrosis $[40,41]$. In the present study, we found that imatinib and nilotinib therapy significantly decreased the expression of PDGFR- $\beta$ with a concomitant decrease in the expression of the gene for PDGF. This inhibitory effect was pronounced on days 14 and 21 . We also confirmed that both imatinib and nilotinib could inhibit PDGF-induced fibroblast proliferation in vitro.

TGF- $\beta$ is a profibrotic factor that increases fibroblast proliferation, stimulates the synthesis and deposition of connective tissue and inhibits connective tissue breakdown [42]. There are three isotypes of TGF- $\beta$ in mammals, TGF- $\beta 1$, TGF- $\beta 2$ and TGF- $\beta 3$, and all exhibit similar biological activity [43]. Although a variety of cell types produce and respond to TGF- $\beta$, tissue fibrosis is primarily attributed to the TGF- $\beta 1$ isoform [44]. TGF- $\beta$ is thought to have a pivotal role in pulmonary fibrogenesis. Transfer of the active gene for TGF- $\beta 1$ induces severe and progressive fibrosis in rodent lungs [45]. Smads are a family of cytoplasmic signal transducer proteins, and Smad 2 and Smad3 predominantly mediate signals from the activated TGF- $\beta$ receptor [46]. Smad7 is an intracellular inhibitor that provides a negative feedback loop [47]. In this study, we confirmed that imatinib and nilotinib therapy significantly decreased the expression of TGF- $\beta 1$ with a concomitant decrease in its gene expression. Nilotinib therapy decreased the expression of $\mathrm{pSmad} 2$ and $\mathrm{pSmad} 3$ and increased Smad7.

The effects of imatinib on pulmonary fibrosis have been reported. Daniels et al. [48] showed that imatinib inhibited the profibrogenic activity of TGF- $\beta$ and attenuated pulmonary fibrosis. Aono et al. [16] also showed that 
imatinib could prevent bleomycin-induced pulmonary fibrosis in mice and inhibit the proliferation of fibroblasts in vitro. Those results are consistent with ours. However, there has been no report about the effect of nilotinib on pulmonary fibrosis and only one report about the effect of nilotinib on dermal fibrosis [49]. To our best knowledge, this study is the first report showing the effects of nilotinib on pulmonary fibrosis.

In our study, the level of TGF- $\beta 1$ was decreased by both imatinib and nilotinib treatments not only in mice sacrificed on days 14 and 21, but also on days 3 and 7 . Following ALI, TGF- $\beta 1$ has been most thoroughly evaluated during the late fibrotic phases of tissue repair [50, 51]. However, some studies showed that TGF- $\beta$ also plays a role during the early phase of ALI [52]. Fahy et al. [30] identified functionally active TGF- $\beta 1$ in BAL fluid from patients with ARDS within the first $24 \mathrm{~h}$ of diagnosis, but this was not evident in normal control subjects. Although we did not measure the active but the latent form of TGF$\beta$, our results are compatible with that report. Imatinib and nilotinib effectively attenuated ALI during the early phase and an accompanying decrease in TGF- $\beta 1$ expression was observed in the imatinib and nilotinib treatment groups on days 3 and 7 .

In our experiment, the antifibrotic effects of imatinib and nilotinib may have arisen from the attenuation of ALI because imatinib and nilotinib were given prophylactically ('preventive model'). To clarify whether imatinib and nilotinib have their own antifibrotic effects, we performed an additional experiment ('therapeutic model'). Imatinib and nilotinib were administered starting on day 7 after bleomycin instillation and the result showed that nilotinib also attenuated fibrosis in a therapeutic model. However, imatinib showed only a trend for attenuation. Thus, the antifibrotic effects of imatinib and nilotinib in a preventive model were partly caused by the attenuation of ALI because the decreases in hydroxyproline level were not as prominent in the therapeutic model as in the preventive model. However, it confirmed that nilotinib exerts its own antifibrotic effect.

There are currently no successful drugs available for treating IPF. Imatinib and nilotinib can give some hope that these drugs can be used for the treatment of IPF because they block the PDGF pathway specifically, and this plays a critical role in the pathogenesis of IPF. However, a recent clinical trial of imatinib for IPF showed negative results [53] in spite of previous positive results in an animal model $[16,48]$. Our study is valuable in that for the first time we have demonstrated a discrepancy in the effects of imatinib between preventive and therapeutic models. This result may explain why imatinib failed clinically in spite of its success in an animal study. Our study clearly showed that imatinib can prevent pulmonary fibrosis when given before the instillation of bleomycin but cannot attenuate it when given after the instillation. IPF is a slowly progressive disease and it is hard to know when the fibrosis process begins or if it is ongoing. Thus, it is almost impossible to give imatinib before the beginning of fibrosis in practice. Based on our results, treating patients with imatinib who are clinically symptomatic for IPF might already be too late and ineffective. However, in our study, nilotinib attenuated pulmonary fibrosis even when given during the ongoing phase of fibrosis. Nilotinib was a more potent antifibrosis agent and attenuated pulmonary fibrosis even without exerting an anti-inflammatory effect. On this point, our study provides novel results and can provide a background for new clinical trials of nilotinib for the treatment of patients with IPF.

According to these results, nilotinib might be a more potent antifibrotic agent than imatinib. Although few data are available for comparing the antifibrotic effect of these two drugs, Shaker et al. [54] recently showed that nilotinib attenuated the progression of liver fibrosis. In that experiment, nilotinib significantly reduced the fibrosis score, but imatinib only showed a trend. That result is well compatible with ours in a therapeutic model. The differences in the antifibrotic effects of imatinib and nilotinib might arise from the potency of nilotinib. Nilotinib was initially developed for those patients resistant to imatinib treatment. Nilotinib has a higher binding affinity and selectivity for c-Abl, resulting in 30 -fold more potency than imatinib [15]. Weisberg et al. [55] also showed that nilotinib can be effective on PDGFR- $\alpha$ mutant gastrointestinal stromal tumor cells that are resistant to imatinib. Thus, this potent activity of nilotinib might result in better antifibrotic effects than the antifibrotic effects of imatinib. Further studies comparing the antifibrotic effects of imatinib and nilotinib are needed.

In summary, this study demonstrated that imatinib and nilotinib treatments attenuated bleomycin-induced ALI and pulmonary fibrosis in mice. The beneficial effect of imatinib and nilotinib was related to the suppression of inflammatory cells and cytokines as well as inhibition of the TGF- $\beta 1$ and PDGF pathways. In a therapeutic model, nilotinib showed a more potent antifibrotic effect than imatinib. Our results provide evidence for the therapeutic potential of imatinib and nilotinib in treating patients with ALI and pulmonary fibrosis. Further investigations are needed into the mechanisms through which imatinib and nilotinib act in these conditions. 


\section{Acknowledgment}

We thank Novartis Pharmaceuticals AG (Basel, Switzerland) for donating the raw drug material for this study. Novartis had no role in the study design, the collection, analysis and interpretation of data, the writing of the report or the decision to submit the paper for publication.

\section{Financial Disclosure and Conflicts of Interest}

None of the authors has a financial relationship with a commercial entity that has an interest in the subject of this manuscript.

\section{References}

1 Ware LB, Matthay MA: The acute respiratory distress syndrome. N Engl J Med 2000; 342:1334-1349.

2 Anonymous: Ventilation with lower tidal volumes as compared with traditional tidal volumes for acute lung injury and the acute respiratory distress syndrome. The Acute Respiratory Distress Syndrome Network. N Engl J Med 2000;342:1301-1308.

$>3$ Lamy M, Fallat RJ, Koeniger E, Dietrich HP, Ratliff JL, Eberhart RC, Tucker HJ, Hill JD: Pathologic features and mechanisms of hypoxemia in adult respiratory distress syndrome. Am Rev Respir Dis 1976;114:267284.

$\checkmark 4$ Tomashefski JF: Pulmonary pathology of the adult respiratory distress syndrome. Clin Chest Med 1990;11:593-619.

$\checkmark 5$ Moore B, Hogaboam CM: Murine models of pulmonary fibrosis. Am J Physiol Lung Cell Mol Physiol 2008;294:L152-L160.

-6 Talpaz M, Silver RT, Druker BJ, Goldman JM, Gambacorti-Passerini C, Guilhot F, Schiffer CA, Fischer T, Deininger MW, Lennard AL, Hochhaus A, Ottmann OG, Gratwohl A, Baccarani M, Stone R, Tura S, Mahon F, Fernandes-Reese S, Gathmann I, Capdeville R, Kantarjian HM, Sawyers CL: Imatinib induces durable hematologic and cytogenetic responses in patients with accelerated phase chronic myeloid leukemia: results of a phase 2 study. Blood 2002;99:19281937.

7 Druker BJ, Talpaz M, Resta DJ, Peng B, Buchdunger E, Ford JM, Lydon NB, Kantarjian H, Capdeville R, Ohno-Jones S, Sawyers CL: Efficacy and safety of a specific inhibitor of the BCR-ABL tyrosine kinase in chronic myeloid leukemia. N Engl J Med 2001;344: 1031-1037.

-8 Manley PW, Cowan-Jacob SW, Buchdunger E, Fabbro D, Fendrich G, Furet P, Meyer T, Zimmermann J: Imatinib: a selective tyrosine kinase inhibitor. Eur J Cancer 2002; 38(suppl 5):S19-S27.

$\checkmark 9$ Day E, Waters B, Spiegel K, Alnadaf T, Manley PW, Buchdunger E, Walker C, Jarai G: Inhibition of collagen-induced discoidin domain receptor 1 and 2 activation by imatinib, nilotinib and dasatinib. Eur J Pharmacol 2008;599:44-53.
10 Pardanani A, Reeder T, Porrata LF, Li C, Tazelaar HD, Baxter EJ, Witzig TE, Cross NC, Tefferi A: Imatinib therapy for hypereosinophilic syndrome and other eosinophilic disorders. Blood 2003;101:3391-3397.

11 Coutr S, Gotlib J: Targeted treatment of hypereosinophilic syndromes and chronic eosinophilic leukemias with imatinib mesylate. Semin Cancer Biol 2004;14:307-315.

12 Griffin JH, Leung J, Bruner RJ, Caligiuri MA, Briesewitz R: Discovery of a fusion kinase in EOL-1 cells and idiopathic hypereosinophilic syndrome. Proc Natl Acad Sci USA 2003;100:7830-7835.

13 Kantarjian H, Giles F, Wunderle L, Bhalla K, O'Brien S, Wassmann B, Tanaka C, Manley P, Rae P, Mietlowski W, Bochinski K, Hochhaus A, Griffin JD, Hoelzer D, Albitar M, Dugan M, Cortes J, Alland L, Ottmann OG: Nilotinib in imatinib-resistant CML and Philadelphia chromosome-positive ALL. N Engl J Med 2006;354:2542-2551.

14 Manley PW, Cowan-Jacob SW, Mestan J: Advances in the structural biology, design and clinical development of Bcr-Abl kinase inhibitors for the treatment of chronic myeloid leukaemia. Biochim Biophys Acta 2005; 1754:3-13.

15 Weisberg E, Manley PW, Breitenstein W, Brüggen J, Cowan-Jacob SW, Ray A, Huntly B, Fabbro D, Fendrich G, Hall-Meyers E, Kung AL, Mestan J, Daley GQ, Callahan L, Catley L, Cavazza C, Azam M, Mohammed A, Neuberg D, Wright RD, Gilliland DG, Griffin JD: Characterization of AMN107, a selective inhibitor of native and mutant BcrAbl. Cancer Cell 2005;7:129-141.

16 Aono Y, Nishioka Y, Inayama M, Ugai M, Kishi J, Uehara H, Izumi K, Sone S: Imatinib as a novel antifibrotic agent in bleomycin-induced pulmonary fibrosis in mice. Am J Respir Crit Care Med 2005;171:1279-1285.

17 Murao Y, Loomis W, Wolf P, Hoyt DB, Junger WG: Effect of dose of hypertonic saline on its potential to prevent lung tissue damage in a mouse model of hemorrhagic shock. Shock 2003;20:29-34.

18 Ashcroft T, Simpson JM, Timbrell V: Simple method of estimating severity of pulmonary fibrosis on a numerical scale. J Clin Pathol 1988;41:467-470.
19 Livak KJ, Schmittgen TD: Analysis of relative gene expression data using real-time quantitative PCR and the $2^{-\Delta \Delta \mathrm{C}_{\mathrm{T}}}$ method. Methods 2001;25:402-408.

20 Cutroneo KR, Sterling KM: A molecular basis for bleomycin-induced pulmonary fibrosis. Chest 1986;89:121S-122S.

21 Aoki Y, Maeno T, Aoyagi K, Ueno M, Aoki F, Aoki N, Nakagawa J, Sando Y, Shimizu Y, Suga T, Arai M, Kurabayashi M: Pioglitazone, a peroxisome proliferator-activated receptor gamma ligand, suppresses bleomycin-induced acute lung injury and fibrosis. Respiration 2009;77:311-319.

22 Chaudhary NI, Schnapp A, Park JE: Pharmacologic differentiation of inflammation and fibrosis in the rat bleomycin model. Am J Respir Crit Care Med 2006;173:769-776.

23 Izbicki G, Segel MJ, Christensen TG, Conner MW, Breuer R: Time course of bleomycininduced lung fibrosis. Int J Exp Pathol 2002; 83:111-119.

24 Janick-Buckner D, Ranges GE, Hacker MP: Alteration of bronchoalveolar lavage cell populations following bleomycin treatment in mice. Toxicol Appl Pharmacol 1989;100: 465-473.

25 Miyachi K, Ihara A, Hankins RW, Murai R, Maehiro S, Miyashita H: Efficacy of imatinib mesylate (STI571) treatment for a patient with rheumatoid arthritis developing chronic myelogenous leukemia. Clin Rheumatol 2003;22:329-332.

26 Eklund K, Joensuu H: Treatment of rheumatoid arthritis with imatinib mesylate: clinical improvement in three refractory cases. Ann Med 2003;35:362-367.

27 Eklund K, Lindstedt K, Sandler C, Kovanen PT, Laasonen L, Juurikivi A, Wolff H, Mykknen M, Joensuu $H$ : Maintained efficacy of the tyrosine kinase inhibitor imatinib mesylate in a patient with rheumatoid arthritis. J Clin Rheumatol 2008;14:294-296.

28 Koyama K, Hatsushika K, Ando T, Sakuma M, Wako M, Kato R, Haro H, Sugiyama H, Hamada Y, Ogawa H, Nakao A: Imatinib mesylate both prevents and treats the arthritis induced by type II collagen antibody in mice. Mod Rheumatol 2007;17:306-310. 
-29 Wolf AM, Wolf D, Rumpold H, Ludwiczek S, Enrich B, Gastl G, Weiss G, Tilg H: The kinase inhibitor imatinib mesylate inhibits TNF- $\alpha$ production in vitro and prevents TNF-dependent acute hepatic inflammation. Proc Natl Acad Sci USA 2005;102: 13622-13627.

30 Fahy RJ, Lichtenberger F, McKeegan CB, Nuovo GJ, Marsh CB, Wewers MD: The acute respiratory distress syndrome: a role for transforming growth factor-beta 1 . Am J Respir Cell Mol Biol 2003;28:499-503.

- 31 Martin C, Papazian L, Payan MJ, Saux P, Gouin F: Pulmonary fibrosis correlates with outcome in adult respiratory distress syndrome. A study in mechanically ventilated patients. Chest 1995;107:196-200.

- 32 Heldin CH, Westermark B: Mechanism of action and in vivo role of platelet-derived growth factor. Physiol Rev 1999;79:12831316.

-33 Jantz MA, Antony VB: Pathophysiology of the pleura. Respiration 2008;75:121-133.

- 34 Antoniades HN, Bravo MA, Avila RE, Galanopoulos T, Neville-Golden J, Maxwell M, Selman M: Platelet-derived growth factor in idiopathic pulmonary fibrosis. J Clin Invest 1990;86:1055-1064.

35 Homma S, Nagaoka I, Abe H, Takahashi K, Seyama K, Nukiwa T, Kira S: Localization of platelet-derived growth factor and insulinlike growth factor I in the fibrotic lung. Am J Respir Crit Care Med 1995;152:2084-2089.

- 36 Aubert JD, Pare PD, Hogg JC, Hayashi S: Platelet-derived growth factor in bronchiolitis obliterans-organizing pneumonia. Am J Respir Crit Care Med 1997;155:676-681.

37 Hertz MI, Henke CA, Nakhleh RE, Harmon KR, Marinelli WA, Fox JM, Kubo SH, Shumway SJ, Bolman RM, Bitterman PB: Obliterative bronchiolitis after lung transplantation: a fibroproliferative disorder associated with platelet-derived growth factor. Proc Natl Acad Sci USA 1992;89:10385-10389.

- 38 Uebelhoer M, Bewig B, Kreipe H, Nowak D, Magnussen H, Barth J: Modulation of fibroblast activity in histiocytosis $\mathrm{X}$ by plateletderived growth factor. Chest 1995; 107:701705 .
39 Vanhee D, Gosset P, Wallaert B, Voisin C, Tonnel AB: Mechanisms of fibrosis in coal workers' pneumoconiosis. Increased production of platelet-derived growth factor, insulin-like growth factor type I, and transforming growth factor $\beta$ and relationship to disease severity. Am J Respir Crit Care Med 1994;150:1049-1055.

40 Yoshida M, Sakuma-Mochizuki J, Abe K, Arai T, Mori M, Goya S, Matsuoka H, Hayashi S, Kaneda Y, Kishimoto T: In vivo gene transfer of an extracellular domain of platelet-derived growth factor beta receptor by the HVJ-liposome method ameliorates bleomycin-induced pulmonary fibrosis. Biochem Biophys Res Commun 1999;265:503508.

41 Rice AB, Moomaw CR, Morgan DL, Bonner JC: Specific inhibitors of platelet-derived growth factor or epidermal growth factor receptor tyrosine kinase reduce pulmonary fibrosis in rats. Am J Pathol 1999;155:213-221.

42 Gharaee-Kermani M, Hu B, Phan SH, Gyetko MR: Recent advances in molecular targets and treatment of idiopathic pulmonary fibrosis: focus on TGF $\beta$ signaling and the myofibroblast. Curr Med Chem 2009;16: 1400-1417.

43 Gorelik L, Flavell RA: Transforming growth factor- $\beta$ in T-cell biology. Nat Rev Immunol 2002;2:46-53.

44 Wynn TA: Cellular and molecular mechanisms of fibrosis. J Pathol 2008;214:199-210.

45 Gauldie J, Bonniaud P, Sime P, Ask K, Kolb M: TGF- $\beta$, Smad 3 and the process of progressive fibrosis. Biochem Soc Trans 2007; 35:661-664.

46 Roberts AB, Tian F, Byfield SD, Stuelten C, Ooshima A, Saika S, Flanders KC: Smad3 is key to TGF- $\beta$-mediated epithelial-to-mesenchymal transition, fibrosis, tumor suppression and metastasis. Cytokine 2006;17: 19-27.
47 Lee SY, Kim JS, Lee JM, Kwon SS, Kim KH, Moon HS, Song JS, Park SH, Kim YK: Inhaled corticosteroid prevents the thickening of airway smooth muscle in murine model of chronic asthma. Pulm Pharmacol 2008;21: 14-19.

- 48 Daniels CE, Wilkes MC, Edens M, Kottom TJ, Murphy SJ, Limper AH, Leof EB: Imatinib mesylate inhibits the profibrogenic activity of TGF- $\beta$ and prevents bleomycin-mediated lung fibrosis. J Clin Invest 2004;114: 1308-1316.

49 Akhmetshina A, Dees C, Pileckyte M, Maurer B, Axmann R, Jngel A, Zwerina J, Gay S, Schett G, Distler O, Distler JH: Dual inhibition of $\mathrm{c}$-abl and PDGF receptor signaling by dasatinib and nilotinib for the treatment of dermal fibrosis. FASEB J 2008;22:22142222.

50 Giri SN, Hyde DM, Hollinger MA: Effect of antibody to transforming growth factor $\beta$ on bleomycin induced accumulation of lung collagen in mice. Thorax 1993;48:959-966.

51 Broekelmann TJ, Limper AH, Colby TV, McDonald JA: Transforming growth factor $\beta 1$ is present at sites of extracellular matrix gene expression in human pulmonary fibrosis. Proc Natl Acad Sci USA 1991;88:6642-6646.

52 Dhainaut J, Charpentier J, Chiche J: Transforming growth factor- $\beta$ : a mediator of cell regulation in acute respiratory distress syndrome. Crit Care Med 2003;31:S258-S264.

53 Daniels CE, Lasky JA, Limper AH, Mieras K, Gabor E, Schroeder DR: Imatinib treatment for idiopathic pulmonary fibrosis: randomized placebo-controlled trial results. Am J Respir Crit Care Med 2010;181:604-610.

54 Shaker ME, Salem HA, Shiha GE, Ibrahim TM: Nilotinib counteracts thioacetamideinduced hepatic oxidative stress and attenuates liver fibrosis progression. Fundam Clin Pharmacol 2011;25:248-257.

55 Weisberg E, Wright RD, Jiang J, Ray A, Moreno D, Manley PW, Fabbro D, Hall-Meyers E, Catley L, Podar K, Kung AL, Griffin JD: Effects of PKC412, nilotinib, and imatinib against GIST-associated PDGFRA mutants with differential imatinib sensitivity. Gastroenterology 2006;131:1734-1742. 